\title{
Review Article \\ Recent Progress of Imprinted Nanomaterials in Analytical Chemistry
}

\author{
Rüstem Keçili (iD) ${ }^{1}$ and Chaudhery Mustansar Hussain (iD) ${ }^{2}$ \\ ${ }^{1}$ Anadolu University, Yunus Emre Vocational School of Health Services, Department of Medical Services and Techniques, \\ 26470 Eskişehir, Turkey \\ ${ }^{2}$ Department of Chemistry and Environmental Science, New Jersey Institute of Technology, Newark, N J 07102, USA
}

Correspondence should be addressed to Chaudhery Mustansar Hussain; chaudhery.m.hussain@njit.edu

Received 27 April 2018; Accepted 3 June 2018; Published 2 July 2018

Academic Editor: Stig Pedersen-Bjergaard

Copyright (C) 2018 Rüstem Keçili and Chaudhery Mustansar Hussain. This is an open access article distributed under the Creative Commons Attribution License, which permits unrestricted use, distribution, and reproduction in any medium, provided the original work is properly cited.

\begin{abstract}
Molecularly imprinted polymers (MIPs) are a type of tailor-made materials that have ability to selectively recognize the target compound/s. MIPs have gained significant research interest in solid-phase extraction, catalysis, and sensor applications due to their unique properties such as low cost, robustness, and high selectivity. In addition, MIPs can be prepared as composite nanomaterials using nanoparticles, multiwalled carbon nanotubes (MWCNTs), nanorods, quantum dots (QDs), graphene, and clays. This review paper aims to demonstrate and highlight the recent progress of the applications of imprinted nanocomposite materials in analytical chemistry.
\end{abstract}

\section{Introduction}

Molecularly imprinted polymers (MIPs) are highly crosslinked robust materials which display excellent affinity towards target compound. For the preparation of MIPs, appropriate functional monomers and a cross-linker agent are polymerized around the target compound (template). The schematic demonstration of the molecular imprinting technique is shown in Figure 1. Due to their high affinity and selectivity for the desired compound, MIPs can be efficiently used in different application areas such as separation, catalysis, and sensor platforms [1-18]. In addition to specific molecular recognition abilities towards their target compound, MIPs can be prepared as composite nanomaterials using nanoparticles, multiwalled carbon nanotubes (MWCNTs), nanorods, quantum dots (QDs), graphene, clays in nanoscale, etc.

This paper provides the recent progress of the applications of imprinted nanocomposite materials in analytical chemistry.

\section{MIPs in SPE Applications}

Solid-phase extraction (SPE) is an efficient sample preparation technique which is one of the most widely applied approach in analytical chemistry. SPE has been first applied in 1940s [19]. Then, the progress for the current analytical applications was initiated in the 1970s. Different conventional materials such as silica based [20, 21], carbon based [22, 23], and clay based [24] resins were widely used in various applications of SPE. Although it is a popular sample preparation technique for the enrichment or extraction of the desired molecules from the complex matrices, the conventional SPE materials used in analytical applications exhibit lower selectivity towards the target molecules that lead to binding of other potentially interfering molecules existing in the sample matrices. This issue is very important especially for the complex biological samples such as urine and blood. MIP-based SPE materials that display great selectivity and binding affinity towards the target molecule/s can overcome the drawbacks of the conventional resins. In addition, MIPs preserve their stability under extreme 


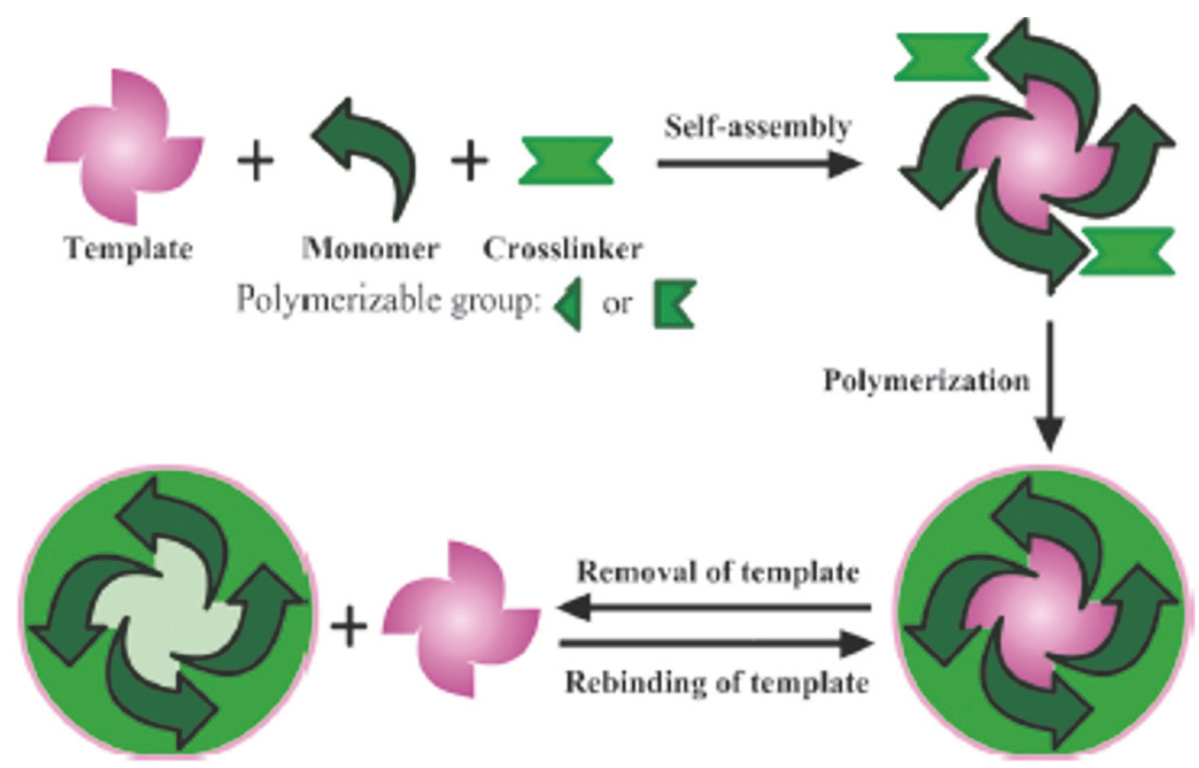

FIGURE 1: Molecular imprinting process (reproduced with permission from [25]).

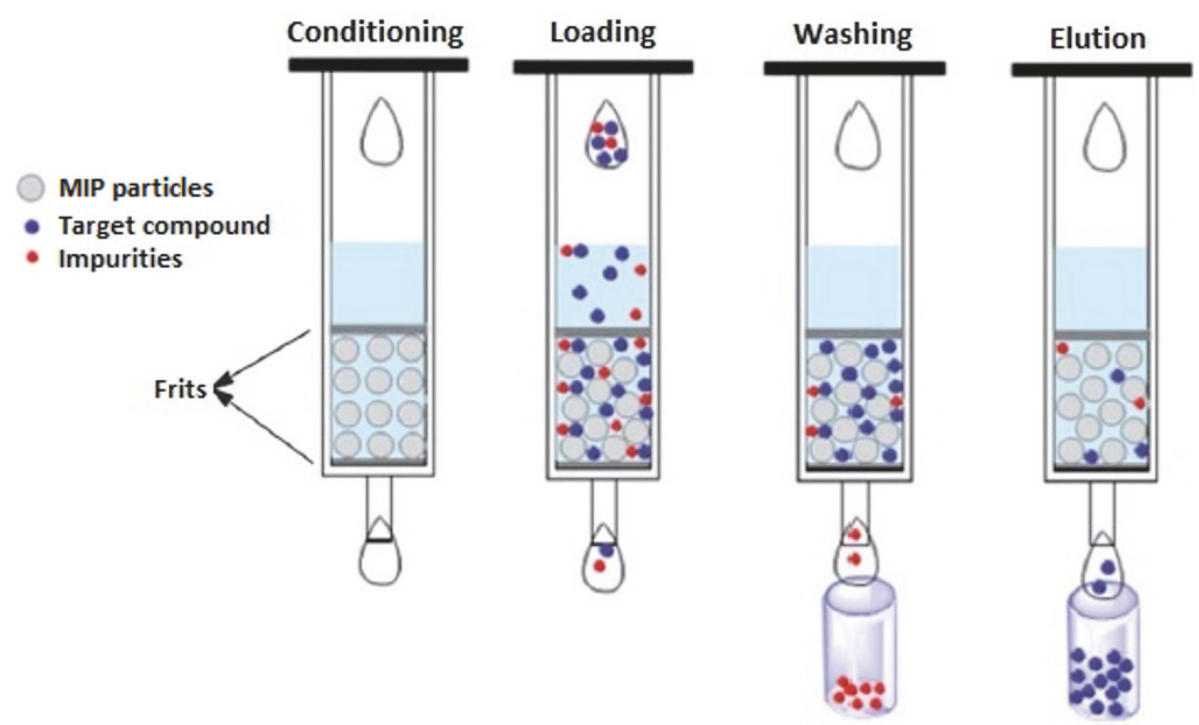

FIGURE 2: Schematic representation of SPE process (reproduced with permission from [26]).

conditions (e.g., high pressure, high temperature, and lower and higher $\mathrm{pH}$ ).

MIP-based SPE process composed of 4 steps is schematically demonstrated in Figure 2.

Sellergren published the first SPE application of MIPs [29]. In the reported study, robust MIPs were developed for the selective extraction of drug compound pentamidine. After this successful application, many MIP-based SPE applications of various compounds in different areas were conducted and reported in the literature [30-41].

In a reported study, $\mathrm{Su}$ et al. developed magnetic MIP nanoparticles for the separation of bovine hemoglobin (Bhb) [114]. In their study, firstly, the preparation of magnetic $\mathrm{Fe}_{3} \mathrm{O}_{4} @ \mathrm{SiO}_{2}$-acrylic acid (AA) nanoparticles were performed. In the second step, the preparation of $\mathrm{BHb}$ imprinted magnetic nanoparticles was carried out by using methacrylic acid (MAA), itaconic acid (IA), and N',Nmethylenebisacrylamide as functional monomers and crosslinker, respectively. The $\mathrm{BHb}$ imprinted magnetic nanoparticles were efficiently used for the extraction of $\mathrm{BHb}$ with high binding capacity $\left(169.29 \mathrm{mgg}^{-1}\right)$.

Viveiros et al. developed a green strategy for the preparation of selective MIPs for acetamide which is a potentially genotoxic impurity in active pharmaceutical ingredients (API) [115]. In their study, silica beads were first functionalized with 3-(Trimethoxysilyl)propyl methacrylate and then MIP layer was synthesized on the modified-silica beads using supercritical $\mathrm{CO}_{2}$ as the green solvent. The prepared 


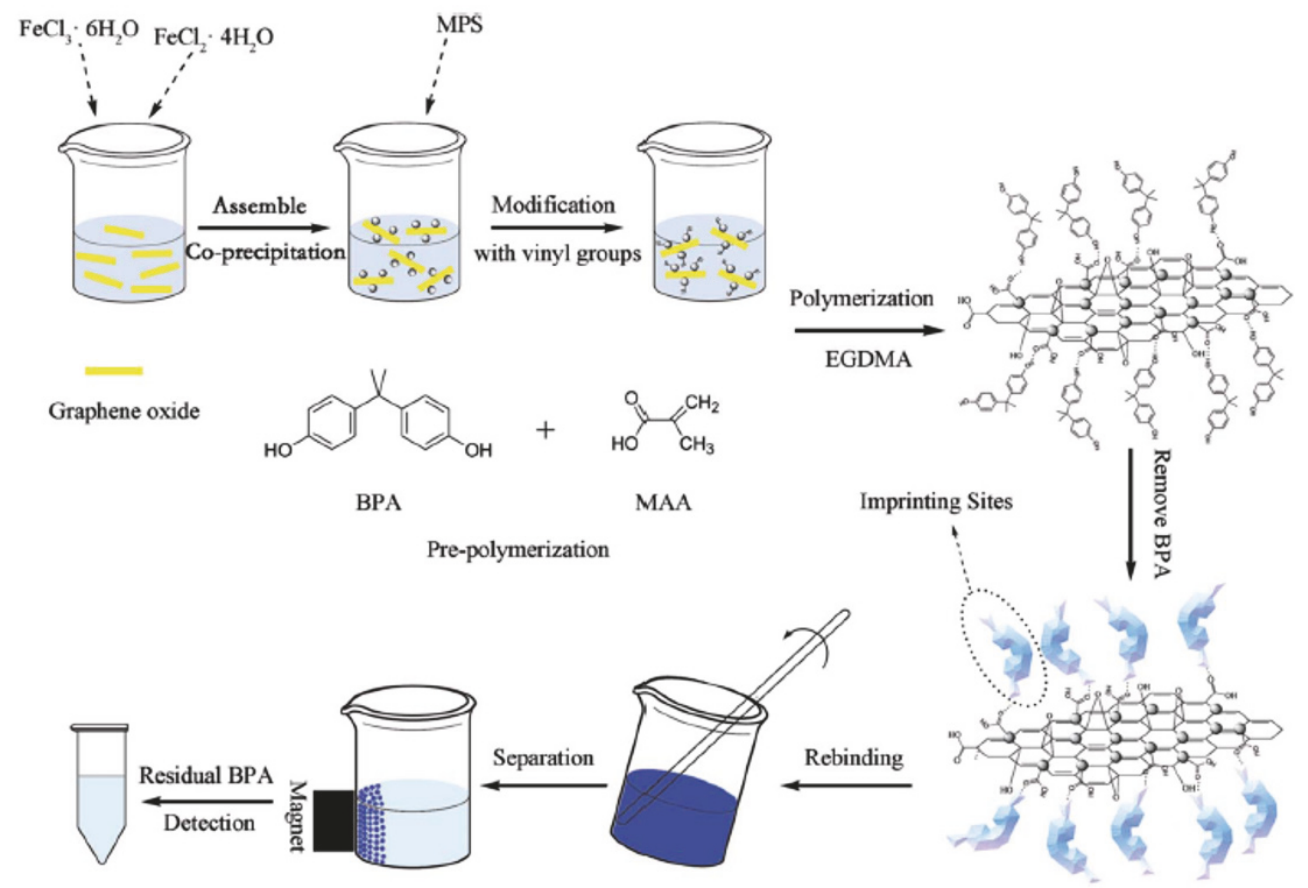

FIGURE 3: Schematic demonstration of the preparation of MIP-based magnetic graphene oxide composite towards BPA and extraction process (reproduced with permission from [27]).

acetamide imprinted polymers were successfully used for the extraction of acetamide from beclomethasone dipropionate which is the model API. The results showed that $100 \%$ of acetamide was removed by using selective MIPs with only very little loss of API (0.37\%).

In another important study, Zhang and colleagues developed magnetic MIP-based-MWCNTs composite materials for the removal of Bisphenol A (BPA) from water matrices [116]. For this purpose, MAA was chosen as the functional monomer. The results from rebinding experiments for BPA in batch mode confirmed that the magnetic MIP-based MWCNTs have excellent affinity towards BPA and the obtained maximum binding capacity was $49.26 \mu \mathrm{molg}^{-1}$.

Yan and colleagues demonstrated the application of $\mathrm{MIP} /$ silica nanocomposites for the recognition of nitrocellulose [117]. The surface of the $\mathrm{SiO}_{2}$ particles was firstly conjugated with -OH groups and 3-(Trimethoxysilyl)propyl methacrylate (MPS) was used for the functionalization of the surface with an acrylyl groups. Then, nitrocellulose (NC) imprinted shell was synthesized on the modified-SiO $\mathrm{S}_{2}$ particles using the functional monomer MAA and crosslinkee ethylene glycol dimethacrylate (EGDMA). The results indicated that MIP/silica nanocomposites exhibited high recognition ability towards $\mathrm{NC}$ with a maximum capacity of $1.7 \mathrm{mgmg}^{-1}$.

In another interesting study reported by Wang and coworkers, selective extraction of BPA was successfully performed by using MIP-based magnetic graphene oxide composites [27]. For this purpose, they firstly prepared magnetic graphene oxide by using coprecipitation approach. Then, MAA (functional monomer) and BPA (template, target compound) were used for the preparation BPA imprinted magnetic graphene oxide composite. The schematic demonstration of the preparation of MIP-based magnetic graphene oxide composite towards BPA and extraction process is shown in Figure 3. The results confirmed that the prepared MIP-based magnetic graphene oxide composite displayed high selectivity towards BPA in the presence of other competing compounds such as phenol and 2,4-dichlorophenol.

Shea and his colleagues prepared imprinted hollow beads for the extraction of $\beta$-estradiol from tap water [118]. For this purpose, $\mathrm{SiO}_{2}$ nanoparticles were used as the sacrificial support. After surface modification with 3(Trimethoxysilyl)propyl methacrylate, selective MIP shell towards $\beta$-estradiol was synthesized on the surface of the $\mathrm{SiO}_{2}$ nanoparticles using the functional monomer MAA and cross-linker EGDMA. The highest binding of $\beta$-estradiol was obtained within a very short time (15 min) with a maximum binding capacity of $44.5 \mu \mathrm{molg}^{-1}$.

In another important study reported by Shen and colleagues [28], $\mathrm{SiO}_{2}$ particles having MIP shell were developed for the SPE of tetrabromobisphenol A (TBBPA) from river water. For this purpose, tetrachlorobisphenol A (TCBPA) was chosen as the dummy template for the preparation of MIP towards TBBPA (Figure 4). The prepared imprinted $\mathrm{SiO}_{2}$ particles showed fast binding kinetics $(20 \mathrm{~min})$ and high binding capacity $\left(230 \mu \mathrm{molg}^{-1}\right)$ towards the target compound TBBPA.

Guo et al. reported that magnetic graphene-based MIP composite was prepared for selective recognition of bovine hemoglobin ( $\mathrm{BHb}$ ) [119]. For this purpose, magnetic graphene was prepared in the first step. Then, MIP layer 


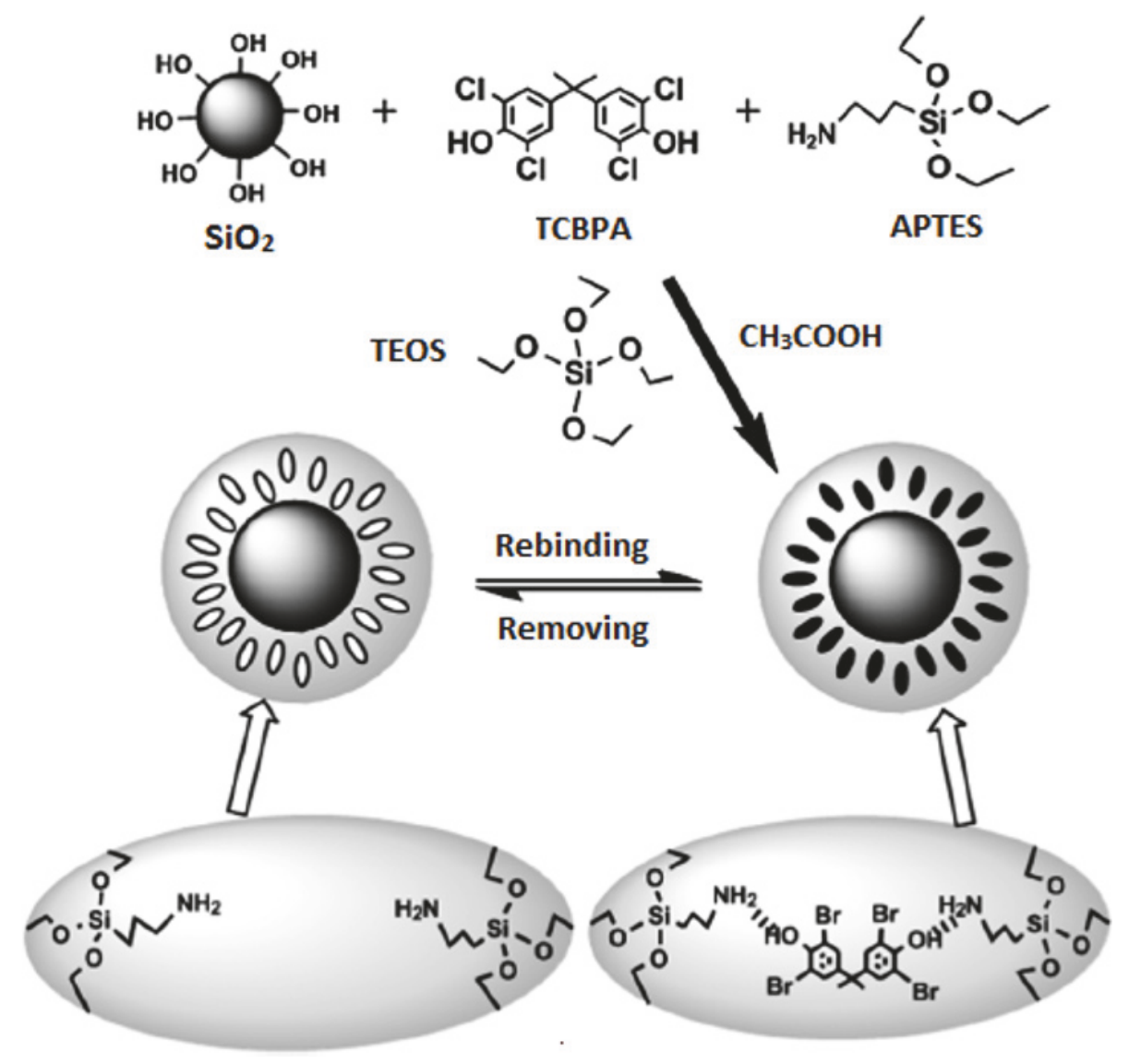

FIgURE 4: Preparation of $\mathrm{MIP} / \mathrm{SiO}_{2}$ composite for TBBPA (reproduced with permission from [28]).

selective to $\mathrm{BHb}$ was prepared using the functional monomer acrylamide (AAm) which has high affinity towards $\mathrm{BHb}$ and cross-linker methylene bisacrylamide (MBA). Maximum binding capacity of the magnetic graphene-based MIP composite for $\mathrm{BHb}$ was found to be as $186.73 \mathrm{mgg}^{-1}$.

Luo et al. developed magnetic graphene-based MIP composite for the removal of 4-nitrophenol (4-NP) from aqueous solutions [120]. $\mathrm{Fe}_{3} \mathrm{O}_{4}$ nanoparticles were immobilized on surface of graphene sheet and magnetic graphene (MGR) was prepared in the first step. Then, MGR/MIPs composite was prepared by polymerization of phenyltriethoxysilane and tetramethoxysilane in the presence of 4-NP. The preparation of the MGR/MIPs composite is demonstrated in Figure 5. The results indicated that the prepared MGR/MIP composite displayed a great binding behavior for 4-NP with an excellent binding capacity $\left(142 \mathrm{mgg}^{-1}\right)$.

In another research by Yang et al., core-shell magnetic MIPs were prepared for selective removal of indole from fuel oil [121]. In their research, magnetic $\mathrm{Fe}_{3} \mathrm{O}_{4}$ nanoparticles were synthesized by using coprecipitation technique. Then, surface of the prepared nanoparticles was coated with $\mathrm{SiO}_{2}$ using 3-(Trimethoxysilyl)propyl methacrylate. In the final step, the functional monomer MAA and EGDMA (crosslinker) were polymerized on the surface of the modified magnetic nanoparticles for the preparation of selective MIP shell towards indole. The results confirmed that the prepared magnetic MIP composite displayed excellent recognition ability towards the target compound indole. The binding capacity of the composite for indole was obtained as 50.25 $\mathrm{mgg}^{-1}$.

In another interesting study [122], Cao et al. prepared MIP-based-MWCNTs for the SPE of perfluorooctanoic acid from aqueous matrices. In their study, they used the functional monomer AAm for the preparation of MIP. After characterization studies, the prepared MIP-based-MWCNTs as composite SPE materials were successfully used for the selective removal of perfluorooctanoic acid from aqueous matrices. The obtained results confirmed that the binding equilibrium was obtained in $80 \mathrm{~min}$. The determined binding capacity was $12.4 \mathrm{mgg}^{-1}$.

Table 1 shows the recent examples of the SPE applications of nanostructured MIP-based composites.

\section{MIPs in Sensor Applications}

MIP-based sensors can be categorized into 3 basic groups: electrochemical, spectroscopic, and piezoelectric sensors. In the following sections, recent examples of MIP-based sensors are briefly explained.

3.1. MIP-Based Electrochemical Sensors. In electrochemical detection, the reaction generally leads to a change of current 

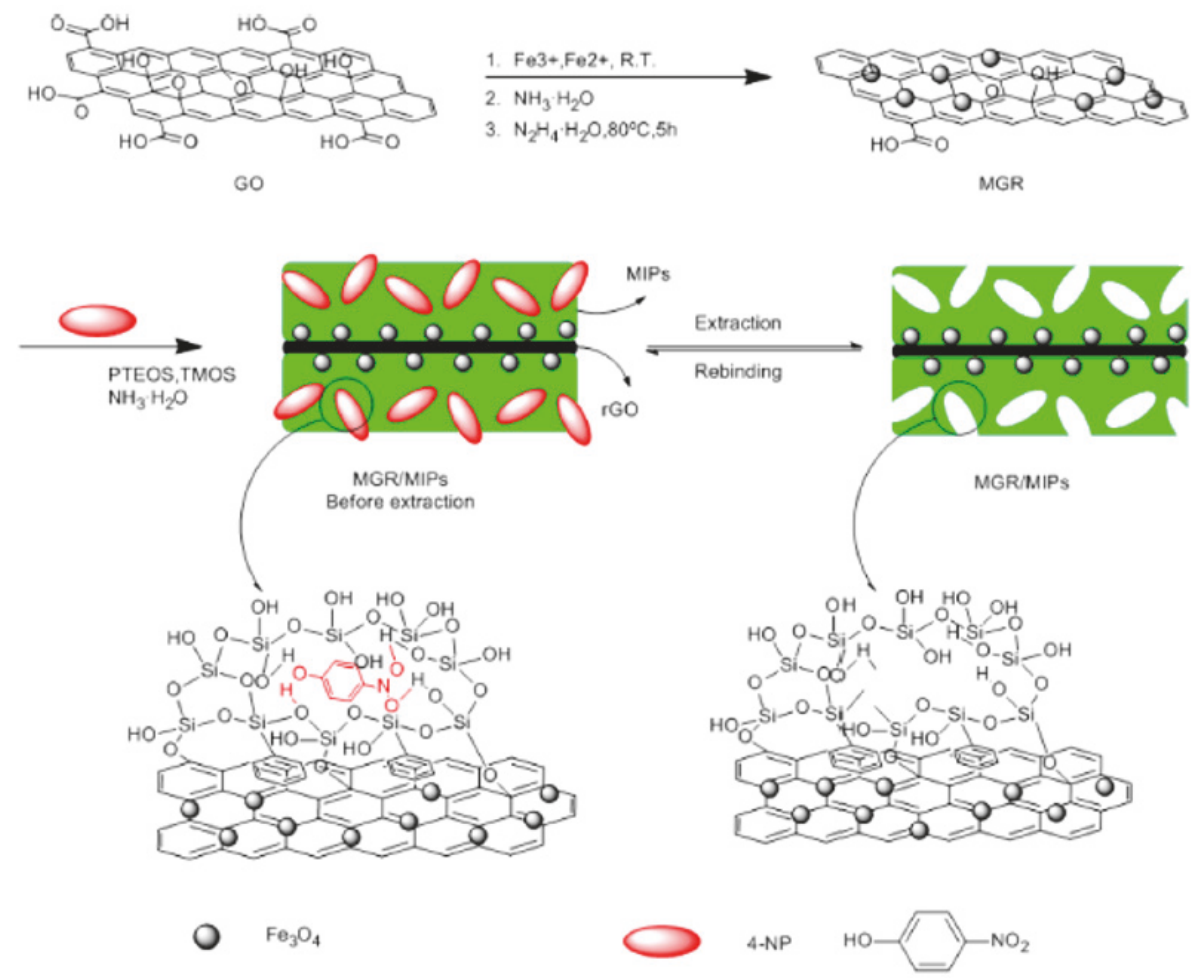

FIGURE 5: Magnetic graphene-based MIP composite towards 4-NP (reproduced with permission from [120]).

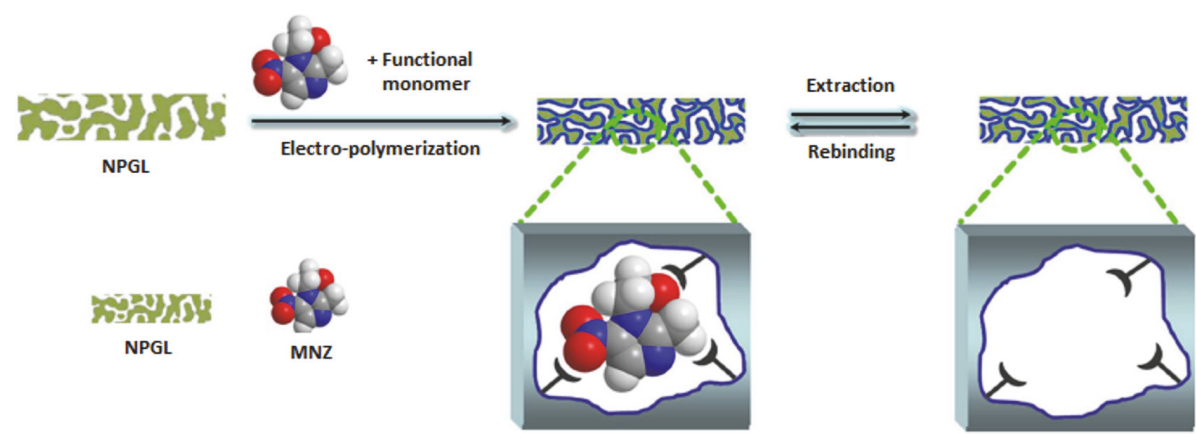

Figure 6: Preparation of MIP-based electrochemical sensor towards MNZ (reproduced from Li et al. (2015) [under the Creative Commons Attribution License/public domain]).

(amperometric), potential (potentiometric), or conductivity (conductometric) [129]. Selectivity and sensitivity are crucial parameter for electrochemical sensors. Surface modification of electrodes in electrochemical sensors by immobilization of recognition components is an efficient approach to obtain a high binding of target compound with good selectivity and good response. The surface modification of electrodes in the design and preparation of electrochemical sensors has firstly been reported by Itaya and Bard in 1978 [130]. Since then, many studies on the design and development of electrochemical sensors in different application areas have been reported.

In a reported study [131], an electrochemical sensor having MIP film for the theophylline recognition was prepared by Kan and colleagues. In their study, the functional monomer o-phenyldiamine was used as the functional monomer for the preparation of MIP film. After MIP film preparation on the glassy carbon electrode surface, gold nanoparticles were immobilized onto MIP film. The prepared MIP-based electrochemical sensor was characterized by SEM and binding behavior towards theophylline was tested using $\mathrm{CV}$, differential pulse voltammetry, and EIS. The detection limit for theophylline was found to be as $1.0 \times 10^{-7} \mathrm{molL}^{-1}$.

$\mathrm{Li}$ and colleagues developed an electrochemical sensor composed of nanoporous gold leaf (NPGL) electrode having selective MIP layer for the detection of metronidazole (MNZ) [132]. The preparation of the MIP-based electrochemical sensor towards MNZ is schematically shown in Figure 6. The 
TABLE 1: Recent examples of nanostructured MIP-based composites in SPE applications.

\begin{tabular}{|c|c|c|c|}
\hline Reference & Nanocomposite composition & Analyte & Sample \\
\hline \multicolumn{4}{|c|}{ Applications to environmental samples } \\
\hline$[42]$ & $\begin{array}{l}\text { Magnetic nanoparticles coated with MIP having the } \\
\text { functional monomer 4-vinyl pyridine (4-VP) }\end{array}$ & $\mathrm{Cr}^{6+}$ & Water \\
\hline$[43]$ & Silica-MIP composite prepared by grafting method & {$\left[\mathrm{UO}_{2}\right]^{2+}$} & Water \\
\hline$[44]$ & $\begin{array}{l}\text { Magnetic nanoparticles coated with MIP having -NH } \\
\text { groups }\end{array}$ & $\mathrm{Co}^{2+}$ & Water \\
\hline [45] & Chitosan-MIP magnetic nanocomposite & $\mathrm{Ni}^{2+}$ & Water \\
\hline$[46]$ & Silica-MIP monolithic composite column & $\alpha$-cypermethrin & Soil \\
\hline [47] & $\mathrm{Cu}(\mathrm{II})$-mediated silica fiber-MIP composite & Thiabendazole & Soil \\
\hline$[48]$ & $\begin{array}{l}\text { Magnetic nanoparticles coated with MIP having MAA } \\
\text { and 4-VP as functional monomers }\end{array}$ & Methyl parathion & Soil \\
\hline$[49]$ & $\begin{array}{l}\text { Magnetic nanoparticles coated with MIP prepared by } \\
\text { using the functional monomer gelatin }\end{array}$ & $17 \beta$-estradiol & Water \\
\hline \multicolumn{4}{|c|}{$\begin{array}{r}\text { Applications to clinical samples } \\
\end{array}$} \\
\hline$[50]$ & $\begin{array}{l}\text { Magnetic } \mathrm{SiO}_{2} \text { nanoparticles having MIP shell prepared } \\
\text { by using the functional monomer MAA }\end{array}$ & Amitriptyline & $\begin{array}{l}\text { Human plasma and } \\
\text { urine }\end{array}$ \\
\hline$[51]$ & Magnetic $\mathrm{SiO}_{2 /} / \mathrm{MIP} /$ chitosan biocomposite & Baclofen & Human urine \\
\hline$[52]$ & $\begin{array}{l}\text { Magnetic nanoparticles having MIP shell prepared by } \\
\text { using the functional monomer MAA }\end{array}$ & Rizatriptan & Human urine \\
\hline$[53]$ & $\begin{array}{l}\text { Magnetic nanoparticles having MIP shell prepared by } \\
\text { using the functional monomer MAA }\end{array}$ & Paracetamol & Human plasma \\
\hline$[54]$ & $\begin{array}{l}\text { Optical fiber coated with MIP prepared by sol-gel } \\
\text { method }\end{array}$ & Caffeine & Human serum \\
\hline [55] & $\begin{array}{l}\text { Magnetic nanoparticles having MIP shell prepared by } \\
\text { using the functional monomer AAm }\end{array}$ & Protoberberine alkaloids & Rat plasma \\
\hline$[56]$ & $\begin{array}{l}\text { Magnetic CNTs coated with MIP having carboxyl } \\
\text { groups }\end{array}$ & Catecholamines & Human plasma \\
\hline$[57]$ & $\begin{array}{l}\text { Magnetic nanoparticles having MIP shell prepared by } \\
\text { using the functional monomer MAA }\end{array}$ & Tizanidine & Human urine \\
\hline$[58]$ & $\begin{array}{l}\text { Magnetic nanoparticles coated with MIP having } \\
\text { aminoimide as the functional monomer }\end{array}$ & Codeine & Human urine \\
\hline [59] & $\begin{array}{l}\text { Silica-MIP composite having AAm, MAA and 4-VP as } \\
\text { functional monomers }\end{array}$ & Baicalin & Rat tissues \\
\hline \multicolumn{4}{|c|}{ Applications to food and beverage samples } \\
\hline$[60]$ & $\begin{array}{l}\text { Carbon QDs-doped MIP monolithic column bearing } \\
\text { the functional monomer MAA }\end{array}$ & Aflatoxin B1 & Peanut \\
\hline$[61]$ & $\begin{array}{l}\text { Magnetic nanoparticles having MIP shell bearing the } \\
\text { functional monomer MAAm }\end{array}$ & Dimethoate & Olive oil \\
\hline$[62]$ & $\begin{array}{l}\text { Magnetic MWCNTs having MIP bearing the functional } \\
\text { monomer MAA }\end{array}$ & Melamine & Milk \\
\hline$[63]$ & $\begin{array}{c}\text { Magnetic nanoparticles having MIP shell prepared by } \\
\text { using ethyl paraoxon as the dummy template }\end{array}$ & $\begin{array}{l}\text { organophosphorus } \\
\text { pesticide }\end{array}$ & Red wine \\
\hline$[64]$ & $\begin{array}{l}\text { Magnetic nanoparticles coated with MIP having AA as } \\
\text { the functional monomer }\end{array}$ & Imidacloprid & Honey and eggplant \\
\hline$[65]$ & $\begin{array}{l}\text { Magnetic nanoparticles coated with MIP having } \\
\text { MAAm and N-3,5-bis(trifluoromethyl) } \\
\text { phenyl-N'-4-vinylphenyl urea as functional monomers }\end{array}$ & Citrinin & Rice \\
\hline$[66]$ & $\begin{array}{l}\text { Magnetic nanoparticles having MIP shell prepared by } \\
\text { using the functional monomer MAA }\end{array}$ & Malachite green & Fish \\
\hline$[67]$ & $\begin{array}{l}\text { Magnetic nanoparticles coated with MIP having oleic } \\
\text { acid }\end{array}$ & Oxytetracycline & Honey, Egg \\
\hline$[68]$ & $\begin{array}{c}\text { Carbon dots coated with MIP prepared by sol-gel } \\
\text { method }\end{array}$ & Sterigmatocystin & Grain \\
\hline
\end{tabular}


TABle 1: Continued.

\begin{tabular}{|c|c|c|c|}
\hline Reference & Nanocomposite composition & Analyte & Sample \\
\hline [69] & $\begin{array}{l}\text { Magnetic nanoparticles coated with MIP having } \\
\text { dopamine as the functional monomer }\end{array}$ & Gallic acid & $\begin{array}{l}\text { Grape, Apple, Peach and } \\
\text { Orange juices } \\
\end{array}$ \\
\hline$[70]$ & $\begin{array}{l}\text { Magnetic nanoparticles coated with MIP having vinyl } \\
\text { groups }\end{array}$ & $\mathrm{Ni}(\mathrm{II})$ & $\begin{array}{c}\text { Cucumber, Cantaloupe, } \\
\text { Apple, Nectarine, Green } \\
\text { beans, Fenugreek, Dill, } \\
\text { Tuna fish }\end{array}$ \\
\hline$[71]$ & $\begin{array}{c}\text { Silica nanoparticles having MIP shell bearing the } \\
\text { functional monomer MAA }\end{array}$ & Ofloxacin & Milk \\
\hline$[72]$ & $\begin{array}{l}\text { Magnetic nanoparticles having MIP shell bearing the } \\
\text { functional monomer dopamine }\end{array}$ & Diethylstilbestrol & Milk \\
\hline$[73]$ & $\begin{array}{l}\text { Magnetic nanoparticles having MIP shell bearing the } \\
\text { functional monomer AAm }\end{array}$ & $\beta$-agonists & Pork \\
\hline$[74]$ & $\begin{array}{l}\text { Magnetic nanoparticles having MIP shell bearing the } \\
\text { functional monomer MAA }\end{array}$ & Chloramphenicol & Honey \\
\hline
\end{tabular}

experimental results confirmed that the developed electrochemical sensor has excellent binding affinity towards MNZ in fish tissue samples. The detection limit was obtained as $1.8 \times 10^{-11} \mathrm{molL}^{-1}$.

In a study reported by Gupta and Goyal, a new graphene/MIP composite sensor for the determination of melatonin in biological samples was prepared [133]. For this purpose, MIP layer was prepared on the glassy carbon electrode (GCE) surface by copolymerization of 4-amino3-hydroxy-1-naphthalenesulfonic acid and melamine around the template melatonin. The optimization studies for MIP layer formation were carried out changing the parameters such as monomer/template ratio and time. After characterization of the prepared composite electrochemical sensor for melatonin by SEM and EIS, the binding performance of the sensor towards target melatonin was carried out by using square wave voltammetry and cyclic voltammetry. The obtained results showed that efficient recognition of melatonin in plasma samples was successfully achieved. The determined detection limit was $0.006 \mu \mathrm{M}$.

Cui et al. prepared graphene-Prussian blue (GR$\mathrm{PB}$ )/MIP-based composite electrochemical sensor for selective detection of butylated hydroxyanisole (BHA) in food samples [123]. In this study, MIP film was synthesized on the surface of GCE having GR-PB by electropolymerization of the functional monomer pyrrole and the template BHA (Figure 7). The prepared composite sensor was characterized by SEM, cyclic voltammetry (CV), electrochemical impedance spectroscopy (EIS), and chronoamperometry. The results obtained from the experiments for the sensor performance showed that immobilization of GR and PB onto the GCE increased the sensor sensitivity and the response towards target BHA. The prepared composite electrochemical sensor showed a linear response towards BHA $\left(9 \times 10^{-8} \mathrm{M}\right.$ to $\left.7 \times 10^{-5} \mathrm{M}\right)$ and the detection limit was calculated as $7.63 \times 10^{-8} \mathrm{M}$.

In an interesting study published by Prasad and colleagues, a composite electrochemical sensor composed of MIP film and MWCNTs was prepared for the detection of Lhistidine [134]. MIP film selective to L-histidine was prepared

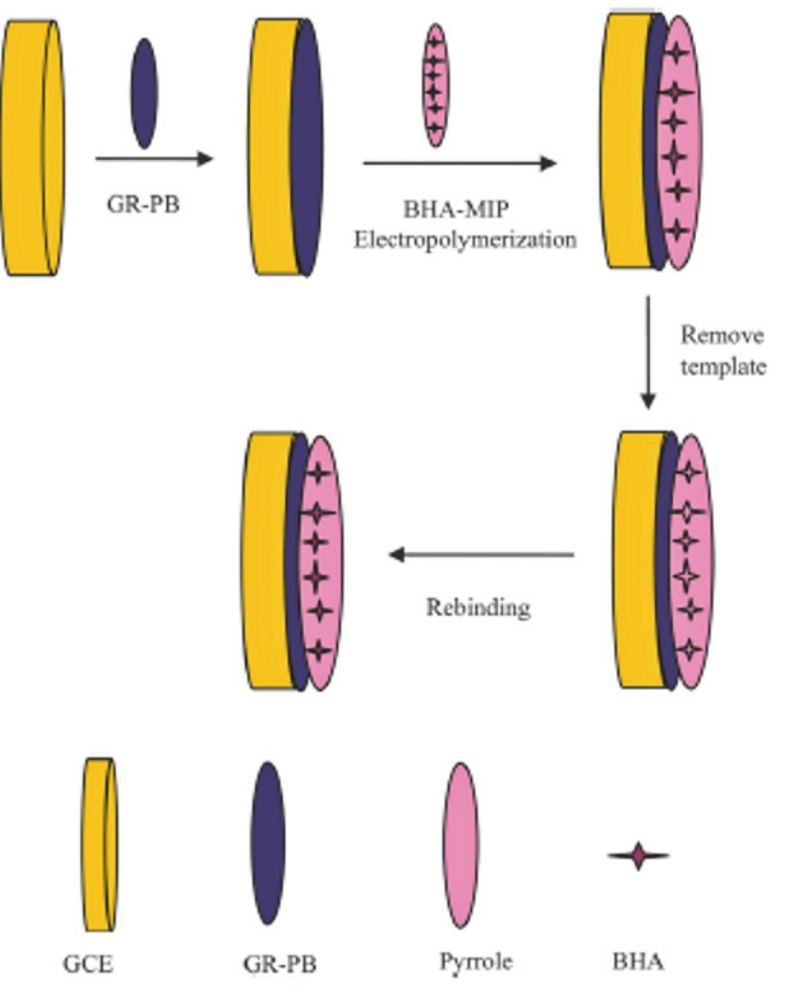

FIGURE 7: GR-PB/MIP-based composite electrochemical sensor towards BHA (reproduced with permission from [123]).

by polymerization of 2-acryl amidoethyl dihydrogen phosphate (functional monomer) and EGDMA (cross-linker). In the first step, the functional monomer was interacted with $\mathrm{Cu}$ (II). Then, polymerization was performed in the presence of $\mathrm{Cu}$ (II)-functional monomer-template complex. The prepared MIP-based electrochemical sensor showed enantioselectivity towards L-histidine and the detection limit was found to be as $1.980 \mathrm{ngmL}^{-1}$. However, cross-reactivity studies of the prepared sensor for potentially interfering compounds in the sample such as L-phenylalanine, D- histidine, 
L- and D-tryptophan, L-tyrosine, L-methionine, L-alanine, L-glycine, L-proline, urea, dopamine, creatinine, uric acid, L-glutamic acid, and L-ascorbic acid were also performed. The results confirmed that the prepared composite electrochemical sensor exhibited very low response towards these interfering compounds.

A carbon nanotube (CNT)/Graphene (GP)/MIP-based composite electrochemical sensor for the detection of bovine serum albumin (BSA) was developed by Chen and colleagues [15]. For this purpose, carbon electrode (CE) was modified with GP in the first step. Then, CNT was prepared on the surface of modified CE with GP. In the final step, MIP membrane was synthesized on the CNT/GP/CE by electrodeposition of aniline in the presence of template BSA. The prepared sensor was successfully applied for sensitive recognition of BSA in human serum with a detection limit of $6.2 \times 10^{-11} \mathrm{gmL}^{-1}$.

Wang and coworkers reported the preparation of CdS quantum dot/graphene/MIP-based electrochemical sensor for selective recognition of 4-aminophenol in water samples [135]. In their study, fluorine-doped tin oxide (FTO) electrode was modified with $\mathrm{CdS}$ quantum dots and graphene (GR). Then, a MIP film selective to target compound 4aminophenol was prepared by electropolymerization. The results confirmed that the developed electrochemical sensor specifically binds the target 4 -aminophenol. The response of the sensor towards 4-aminophenol was linear in the concentration range of $5.0 \times 10^{-8} \mathrm{M}$ to $3.5 \times 10^{-6} \mathrm{M}$ and the determined detection limit was $2.3 \times 10^{-8} \mathrm{M}$.

3.2. MIP-Based Spectroscopic Sensors. MIP-based spectroscopic sensors can be divided into 3 categories. These are MIP-based-fluorescence sensors, MIP-based-chemiluminescence sensors, and MIP-based-SPR sensors. In the fluorescence based molecular recognition of the target compound, fluorescence functional monomers are chosen for the fabrication of sensor platforms based on molecular imprinting technique [136]. When the target compound binds to the sensor, fluorescence intensity increases or decreases depending on the sensor design.

In a significant research reported by Zhang and colleagues [137], CdSe/ZnS quantum dots (QDs) coated with MIP film which shows fluorescence feature were synthesized for the sensitive recognition of carbaryl in cabbage and rice samples. For this purpose, MAA was used as the functional monomer for the synthesis of MIP layer on the QDs surface modified with the ionic liquid. The obtained results from the fluorescence measurements showed that the fluorescence sensor composed of $\mathrm{QD}_{\mathrm{S}}-\mathrm{MIP}$ exhibited high recognition ability towards carbaryl in the presence of metolcarb and isorcarb which are analogues of carbaryl.

Mehrzad-Samarin et al. developed a novel graphene QDs embedded silica MIP-based fluorescence sensor for the selective recognition of metronidazole [138]. The prepared sensor showed a linear response towards metronidazole in the range between $0.2 \mu \mathrm{M}$ and $15 \mu \mathrm{M}$. The determined detection limit was $0.15 \mu \mathrm{M}$.

$\mathrm{Li}$ and coworkers developed magnetic silica nanoparticles having selective MIP shell for the recognition of Rhodamine B from aqueous samples [139]. In this study, magnetic silica nanoparticles were coated with MIP layer using nitrobenzoxadiazole which is a fluorophore molecule. The obtained results confirmed that the efficient detection of Rhodamine $\mathrm{B}$ in aqueous samples was performed by using MIP-based magnetic silica nanoparticles. The maximum binding of Rhodamine $\mathrm{B}$ was obtained in $60 \mathrm{~min}$ with a high binding capacity $\left(29.64 \mathrm{mgg}^{-1}\right)$.

In another study reported by Jalili and Amjadi [140], MIP/green emitting carbon dot composite was prepared for the selective recognition of 3-nitrotyrosine which is a biomarker for various diseases such as rheumatoid arthritis, Alzheimer, atherosclerosis, osteoarthritis, and cardiovascular diseases. The prepared MIP-based composite fluorescence sensor was efficiently used for the selective recognition of 3nitrotyrosine in human serum samples in the concentration range from 0.05 to $1.85 \mu \mathrm{M}$ and the detection limit was obtained as $17 \mathrm{nM}$.

The research group of $\mathrm{Hu}$ was developed a $\mathrm{ZnS}$ QDs/MIPbased fluorescence nanosensor for the sensitive detection of sulfapyridine in tap water samples [124]. For this purpose, Mn-doped ZnS QDs was used as the fluorescence core and MIP shell was prepared on the surface of the QDs by using the functional monomer MAA, cross-linker EDMA, initiator AIBN, and template sulfapyridine (SPD). The schematic demonstration of the preparation of $\mathrm{ZnS}$ QDs/MIP-based fluorescence nanosensor towards sulfapyridine is shown in Figure 8. The prepared ZnS QDs/MIP-based fluorescence nanosensor exhibited high recognition ability towards SPD with a detection limit of $0.5 \mu \mathrm{M}$.

Chemiluminescence is another efficient approach that is used for the investigation of the recognition performance of MIP-based spectroscopic sensor systems. In this approach, a chemiluminescence system is chosen and selective MIPs are integrated to this system. When target compound binds to the MIP-based sensor, chemiluminescence emission is generated. The amount of the emission depends on the amount of bound target compound to the sensor surface.

In a study conducted by Wang and coworkers [125], a magnetic graphene oxide (GO)/MWCNTs/MIP-based chemiluminescence nanosensor was developed for the sensitive detection of lysozyme in egg samples. Figure 9 shows the schematic demonstration of the construction of the magnetic GO/MWCNTs/MIP-based chemiluminescence nanosensor towards lysozyme. The developed chemiluminescence nanosensor displayed high sensitivity towards lysozyme. The obtained detection limit was $1.9 \times 10^{-9} \mathrm{gmL}^{-1}$.

SPR-based sensor platforms are also popular recognition systems. SPR technique relies on the measurement of the changes in refractive index of thin layer on the metal surface. The recognition element on the surface of the sensor is usually gold or silver coated with thin film. Therefore, uniform film layer is synthesized on the surface of MIP-based-SPR sensors.

Many studies were published on the development of MIP-based SPR sensors and their applications. For example, the group of Piletsky developed a molecularly imprinted nanoparticle-based SPR sensor system for the sensitive detection of diclofenac in aqueous solutions [141]. For this purpose, diclofenac imprinted nanoparticles were synthesized by using 


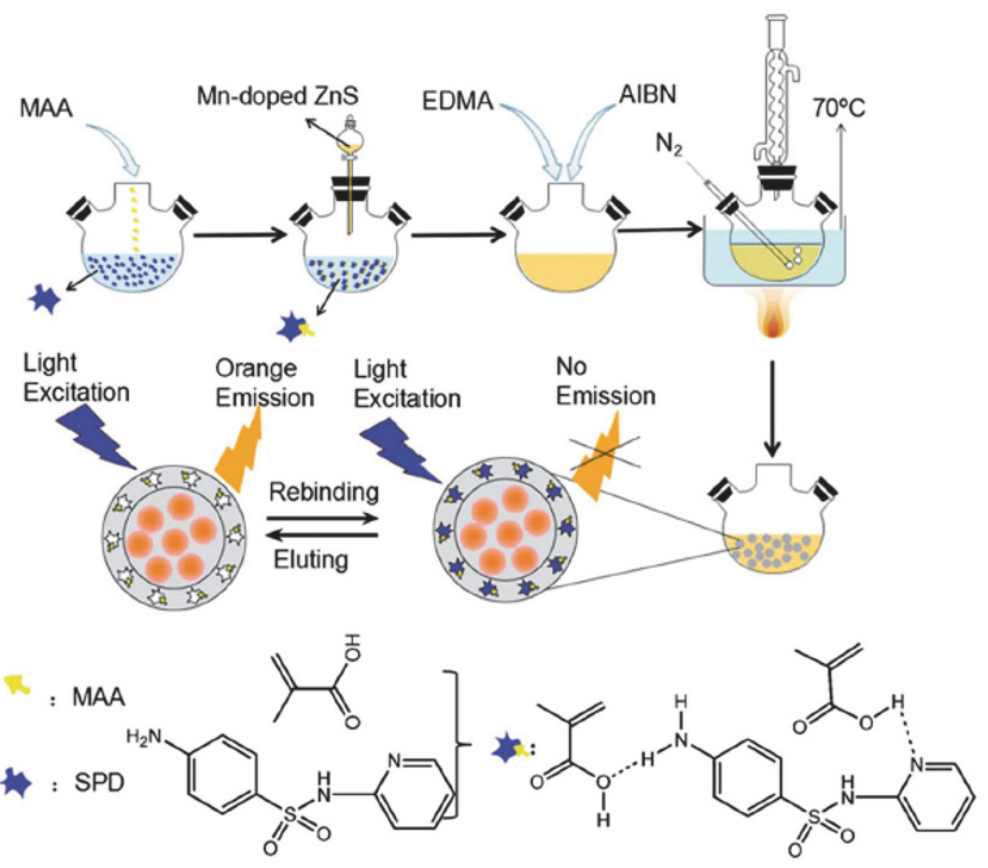

FIGURE 8: The preparation of ZnS QDs/MIP-based fluorescence nanosensor towards sulfapyridine (reproduced with permission from [124]).

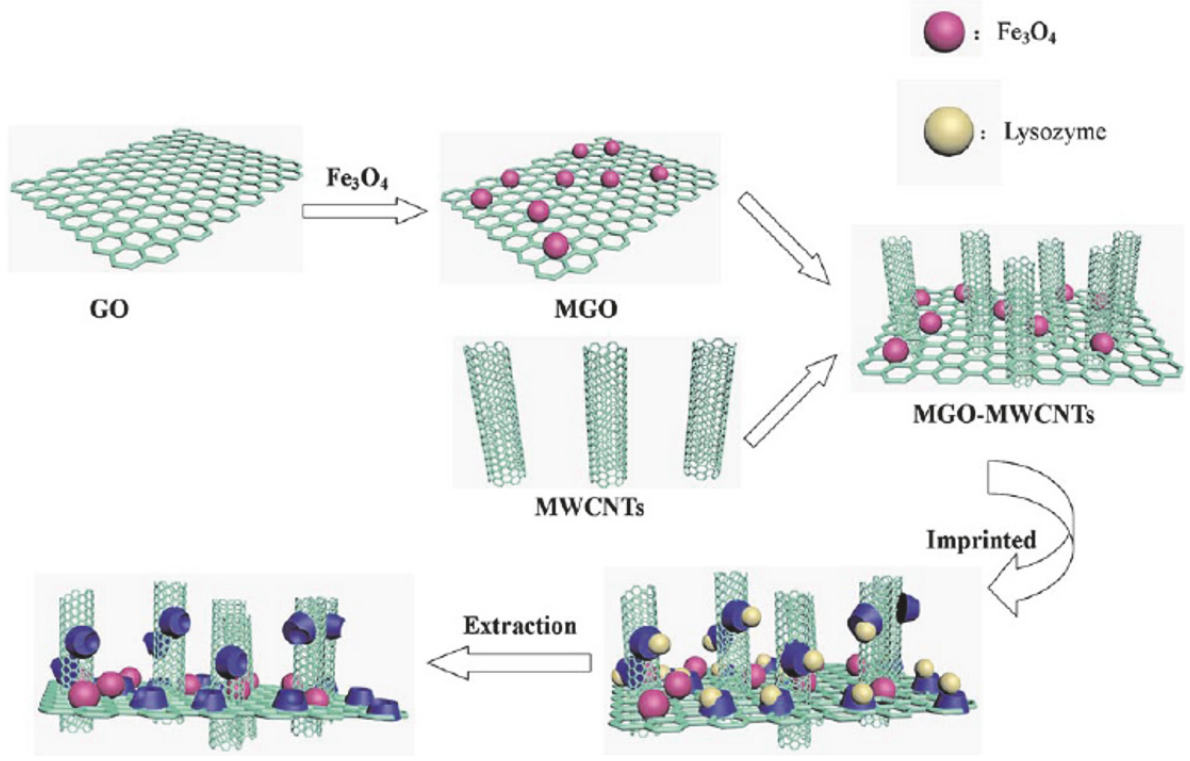

FIGURE 9: Schematic depiction of the preparation of magnetic GO/MWCNTs/MIP-based chemiluminescence nanosensor towards lysozyme (reproduced with permission from [125]).

styrene as the functional monomer, EGDMA and trimethylolpropane trimethacrylate (TRIM) as cross-linkers, and pentaerythritol tetrakis (3-mercaptopropionate) as the chain transfer agent. Then, the surface of the SPR sensor was activated by using N-Hydroxysuccinimide (NHS) and 1-Ethyl3-(3-dimethylaminopropyl)-carbodiimide (EDC). After activation step, the prepared diclofenac imprinted nanoparticles were immobilized onto the surface of the sensor. The sensitive detection of diclofenac was successfully achieved in the concentration range from 1.24 to $80 \mathrm{ngmL}^{-1}$. The selectivity of the SPR sensor towards diclofenac in the presence of propranolol and vancomycin was also studied. The experimental data confirmed that the sensor exhibited high selectivity towards diclofenac. 


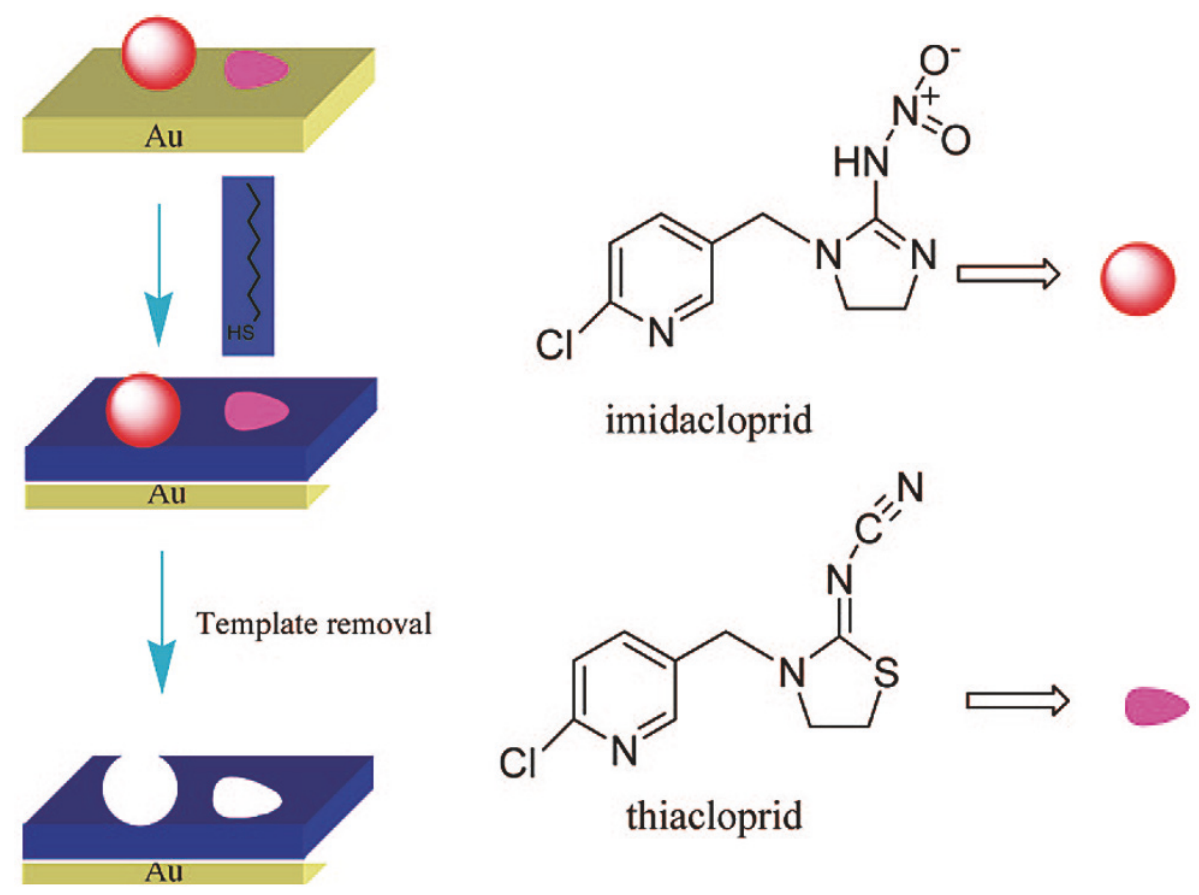

FIGURE 10: MIP-based QCM sensor towards imidacloprid and thiacloprid (reproduced with permission from [126]).

In another interesting study [142], Ashley et al. prepared a MIP-based SPR nanosensor for the sensitive detection of $\alpha$-casein cleaning in place (CIP) wastewater samples. For this purpose, immobilization of the target protein $\alpha$ casein (template) on the surface of glass nanobeads was carried out in the first step. Then, MIP nanoparticles were prepared by using N-(3-aminopropyl)-methacrylamide, the functional monomer acrylic acid, and cross-linker $\mathrm{N}, \mathrm{N}^{\prime}$-methylenebis(acrylamide). Finally, $\alpha$-casein imprinted nanoparticles were incorporated onto the SPR sensor surface. The results confirmed that the developed MIP-based SPR nanosensor showed excellent selectivity and affinity $\left(\mathrm{K}_{\mathrm{D}} \sim\right.$ $10 \times 10^{-9} \mathrm{M}$ ) towards target protein $\alpha$-casein. The detection limit was obtained as $127 \mathrm{ngmL}^{-1}$.

3.3. MIP-Based Piezoelectric Sensors. Quartz crystal microbalance (QCM) is another popular an analytical technique that displays high sensitivity to mass changes on the sensor surface. Many examples on different applications of QCM sensor systems have been reported in the literature and some examples are briefly described in the following.

Eren et al. [143] developed a QCM sensor system having MIP layer for the detection of lovastatin in red yeast rice. MIP layer was prepared on the surface of allyl mercaptan modified-gold electrode by the polymerization of HEMA, MAAsp as the functional monomers, and crosslinker EGDMA in the presence of template compound lovastatin. The developed QCM sensor having MIP layer was successfully applied for the sensitive recognition of lovastatin in red yeast rice samples. The limit of detection of the prepared QCM sensor towards lovastatin was found to be as $0.030 \mathrm{nM}$.
A QCM having MIP layer towards profenofos was developed by Gao and coworkers [144]. For this purpose, they used MAA as the functional monomer for the synthesis of profenofos imprinted MIP layer on the surface of gold electrode modified with 11-mercaptoundecanoic acid. The developed QCM sensor with MIP layer showed high sensitivity towards the target compound profenofos in aqueous solutions with an excellent detection limit of $2.0 \times 10^{-7} \mathrm{mgmL}^{-1}$.

In another study [126], Bi and Yang prepared a QCM sensor platform bearing MIP layer for the detection of pesticide compounds imidacloprid and thiacloprid in celery juice. For this purpose, the immobilization of the target compounds on the surface of the gold chip was performed in the first step. Then, self-assembly of alkanethiols around the target compounds was carried out and the template removal was performed by using EtOH. The demonstration of the QCM sensor bearing MIP layer towards imidacloprid and thiacloprid is shown in Figure 10. The developed sensor system displayed good recognition behavior towards the target compounds imidacloprid and thiacloprid. It has also been noted that these sensor systems are promising and have the potential to detect pesticide residues in aqueous solutions and vegetables.

In another interesting study [145], the detection of metolcarb in food and beverage samples such as cabbage, pear, and apple juice was carried out by using MIP-based QCM sensor. The results indicated that the developed QCM sensor displayed a linear response towards metolcarb in the range between 5 and $70 \mu \mathrm{gL}^{-1}$. The detection limit was obtained as $2.309 \mu \mathrm{gL}^{-1}$.

Table 2 shows the recent examples of nanostructured MIP-based composites in sensor applications. 


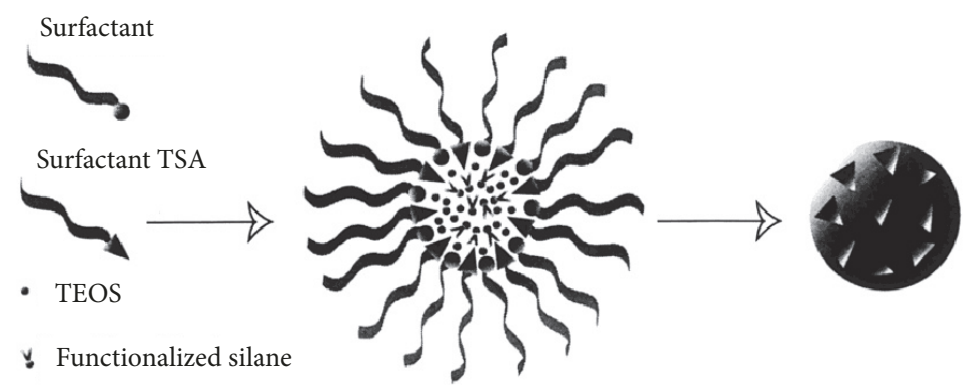

FIGURE 11: Preparation on MIP-based silica nanoparticles (reproduced with permission from [127]).

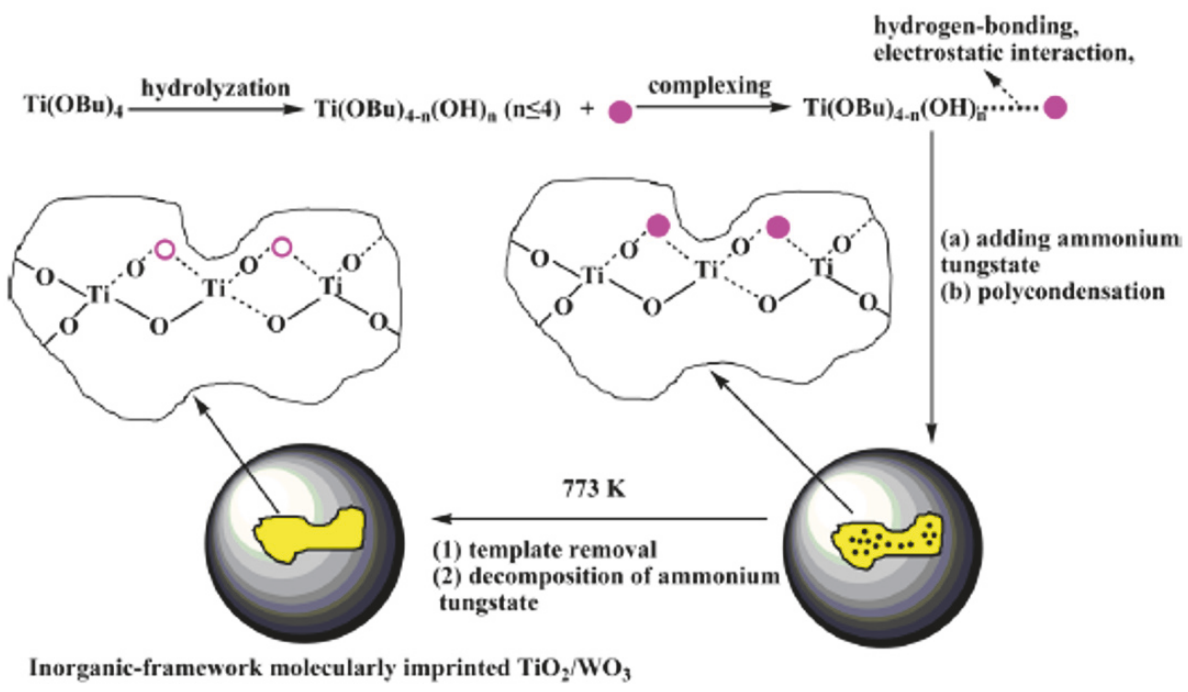

- template molecule $\quad \mathrm{O}$ - imprinted site

Figure 12: $\mathrm{TiO}_{2} / \mathrm{WO}_{3} / \mathrm{MIP}$-based composite nanocatalyst towards 2-nitrophenol and 4-nitrophenol (reproduced with permission from $[128])$.

\section{MIPs in Catalytic Applications}

Enzyme-like catalysts are also popular application of imprinted nanomaterials in biomimetic catalysis. For the preparation of enzyme-like catalysts based on molecular imprinting approach, appropriate functional monomers are chosen and incorporated in the polymeric network by choosing the substrate of enzyme (as the template compound) or the transition state analogue (TSA) of the target reaction. After removal of the template from the polymeric network, the obtained imprinted nanomaterial behaves as enzyme-like catalyst towards the desired chemical or biochemical reaction. Some examples reported in the literature are briefly discussed in the following.

Markowitz and coworkers developed MIP-based silica nanocomposites for the selective hydrolysis of substrates of chymotrypsin and trypsin [127]. For this purpose, a TSA of $\alpha$-chymotrypsin was used as the template compound for the preparation of $\alpha$-chymotrypsin-like nanocatalyst (Figure 11). The silane groups conjugated with the amino acids which exist in the catalytic center of the $\alpha$-chymotrypsin were used for the preparation of silica nanoparticles. The activity of the prepared MIP-based silica nanocomposites was performed by monitoring the hydrolysis of the substrates succinylAla-Ala-Pro-Phe- $p$-nitroanilide and benzoyl-DL-arginine- $p$ nitroanilide. The developed imprinted nanocatalyst showed great enantioselective hydrolytic activity towards the substrate compounds.

Luo et al. developed a $\mathrm{TiO}_{2} / \mathrm{WO}_{3} / \mathrm{MIP}$-based composite nanocatalyst for the efficient degradation of 2-nitrophenol and 4-nitrophenol [128]. One-step sol-gel method was applied for the preparation of composite nanocatalyst by using tetrabutyl orthotitanate which was chosen as the functional monomer precursor and titanium source. The schematic representation of the prepared composite nanocatalyst is shown Figure 12.

The obtained results indicated that the photocatalytic activity of the prepared $\mathrm{TiO}_{2} / \mathrm{WO}_{3} / \mathrm{MIP}$-based composite nanocatalyst towards the target compounds is 2 times higher than its corresponding nonimprinted catalyst.

In a study reported by Bonomi et al. [146], catalytic imprinted nanogels were synthesized for the Kemp 
TABLE 2: Recent examples of nanostructured MIP-based composites in sensor applications.

\begin{tabular}{|c|c|c|c|}
\hline Reference & Nanocomposite composition & Analyte & Sample \\
\hline \multicolumn{4}{|c|}{ Electrochemical sensors } \\
\hline [75] & $\begin{array}{l}\text { Pencil graphite electrode coated with molecularly } \\
\text { imprinted polypyrrole }\end{array}$ & Methylimidazole & Serum \\
\hline [76] & $\begin{array}{l}\text { Glassy carbon electrode modified with graphene/ Au } \\
\text { nanoparticles/MIP composite }\end{array}$ & Colchicine & $\begin{array}{c}\text { Serum and } \\
\text { pharmaceuticals }\end{array}$ \\
\hline$[77]$ & $\begin{array}{l}\text { Glassy carbon electrode modified with graphene/Ag } \\
\text { nanoparticles/MIP composite }\end{array}$ & Creatinine & Saliva and serum \\
\hline$[78]$ & $\begin{array}{l}\text { Glassy carbon electrode coated with CNT/MIP } \\
\text { composite }\end{array}$ & Tramadol & Urine \\
\hline$[79]$ & Carbon paste electrode coated with MIP & $\mathrm{Zn}^{2+}$ & $\begin{array}{l}\text { River water, urine and } \\
\text { blood }\end{array}$ \\
\hline [80] & Graphite electrode coated with MIP & Azithromycin & Drug \\
\hline$[16]$ & $\begin{array}{l}\text { Glassy carbon electrode coated with graphene/ } \\
\text { CNT/MIP composite }\end{array}$ & Propyl gallate & Vegetable oil \\
\hline$[81]$ & $\begin{array}{c}\text { Carbon paste electrode coated with CNT/MIP } \\
\text { nanoparticle composite }\end{array}$ & Meloxicam & Plasma \\
\hline [82] & $\begin{array}{l}\text { Glassy carbon electrode coated with MIP/Pd } \\
\text { nanoparticles composite }\end{array}$ & Norepinephrine & Urine \\
\hline [83] & Carbon paste electrode coated with MIP & Famciclovir & Drug \\
\hline$[84]$ & $\begin{array}{l}\text { Glassy carbon electrode coated with graphene/MIP } \\
\text { membrane composite }\end{array}$ & Artemisinin & Plant extract \\
\hline$[85]$ & $\begin{array}{l}\text { Glassy carbon electrode coated with MIP/Au } \\
\text { nanoparticles composite }\end{array}$ & Estradiol & Milk \\
\hline$[86]$ & $\begin{array}{l}\text { Interdigitated electrode coated with CNT/MIP } \\
\text { composite } \\
\end{array}$ & Cotinine & Organic solutions \\
\hline [87] & $\begin{array}{l}\text { Glassy carbon electrode coated with CNT/MIP/Pt } \\
\text { nanoparticles composite }\end{array}$ & Tartrazine & Beverages \\
\hline$[88]$ & $\begin{array}{l}\text { Carbon electrode coated with graphene/MIP/Ni } \\
\text { nanoparticles composite }\end{array}$ & Tetrabromo bisphenol A & $\begin{array}{l}\text { Tap water, rain and } \\
\text { lake water }\end{array}$ \\
\hline [89] & $\begin{array}{l}\text { Carbon electrode coated with graphene/MIP/Ag } \\
\text { nanoparticles composite }\end{array}$ & Bisphenol A & $\begin{array}{l}\begin{array}{l}\text { Plastic samples and } \\
\text { soil samples }\end{array} \\
\end{array}$ \\
\hline$[90]$ & Carbon paste electrode coated with MIP & Trinitrotoluene & $\begin{array}{l}\text { Tap water and sea } \\
\text { water }\end{array}$ \\
\hline \multicolumn{4}{|c|}{ Spectroscopic sensors } \\
\hline [91] & $\begin{array}{l}\text { CdTe QDs embedded-SiO }{ }_{2} \text { particles coated with MIP } \\
\text { layer }\end{array}$ & Neomycin & $\begin{array}{c}\text { Pork, swine liver, } \\
\text { swine kidney, fish } \\
\text { meat, fish liver, } \\
\text { chicken meat, chicken } \\
\text { kidney and milk }\end{array}$ \\
\hline$[92]$ & CdSe/ZnS QDs having MIP shell & Trichlorfon & $\begin{array}{l}\text { Spinach and rape } \\
\text { samples }\end{array}$ \\
\hline$[93]$ & $\begin{array}{l}\text { Luminescent magnetic MIP nanoparticles having } \\
\qquad \mathrm{LaVO}_{4}: \mathrm{Eu}^{3+} \text { nanocrystals }\end{array}$ & Diazinon & Aqueous solutions \\
\hline$[94]$ & $\begin{array}{c}\text { Chemiluminescent } \mathrm{Fe}_{3} \mathrm{O}_{4} @ \mathrm{SiO}_{2} \text { magnetic } \\
\text { nanoparticles coated with MIP layer }\end{array}$ & Sulfadiazine & Urine \\
\hline$[95]$ & $\begin{array}{l}\text { SPR sensor having MIP layer bearing the functional } \\
\text { monomer MAA }\end{array}$ & Clenbuterol & Aqueous solutions \\
\hline$[96]$ & $\begin{array}{l}\text { SPR sensor having MIP layer bearing the functional } \\
\text { monomer MAA }\end{array}$ & Ametryn & Soybean and rice \\
\hline [97] & ZnS QDs doped with Mn/MIP composite & Domoic acid & Shellfish \\
\hline$[98]$ & $\begin{array}{c}\mathrm{ZnO} \text { nanorods coated with molecularly imprinted } \\
\text { poly(ethylene-co-vinylalcohol) }\end{array}$ & Melatonin & Urine \\
\hline [99] & $\begin{array}{l}\text { Magnetic nanoparticles having MIP layer bearing the } \\
\text { functional monomer MAA }\end{array}$ & Mefenamic acid & Aqueous solutions \\
\hline$[100]$ & $\begin{array}{c}\text { SPR sensor surface having MIP layer bearing the } \\
\text { functional monomer MAA }\end{array}$ & L-nicotine & Aqueous solutions \\
\hline
\end{tabular}


TABLE 2: Continued.

\begin{tabular}{|c|c|c|c|}
\hline Reference & Nanocomposite composition & Analyte & Sample \\
\hline$[101]$ & Graphene QDs coated with MIP layer & Dopamine & Serum and Urine \\
\hline \multicolumn{4}{|c|}{$\begin{array}{rr} & \text { Piezoelectric sensors } \\
\end{array}$} \\
\hline [102] & $\begin{array}{c}\text { QCM sensor surface coated with } \\
\text { 1,3,5-pentanetricarboxylic acid imprinted film }\end{array}$ & Domoic acid & Mussel extracts \\
\hline [103] & $\begin{array}{l}\text { QCM sensor surface coated with MIP film having } \\
\text { styrene/DVB copolymer }\end{array}$ & Terpenes & Herbs \\
\hline$[104]$ & $\begin{array}{l}\text { QCM sensor surface coated with MIP film having } 1,3,5 \\
\text { trisacrylamide 2,4,6 triazine as the functional monomer }\end{array}$ & Folic acid & Aqueous solutions \\
\hline [105] & $\begin{array}{l}\text { QCM sensor having MIP layer bearing the functional } \\
\text { monomer MAA }\end{array}$ & $\mathrm{Ni}^{2+}$ and $\mathrm{Cu}^{2+}$ & Aqueous solutions \\
\hline [106] & $\begin{array}{l}\text { QCM sensor surface coated with polythiophene MIP } \\
\text { film }\end{array}$ & Pinacolyl methyl phosphonate & Aqueous solutions \\
\hline [107] & $\begin{array}{l}\text { QCM sensor surface having MIP/Au nanoparticles/ } \\
\text { poly(o-aminothiophenol) membrane }\end{array}$ & Ractopamine & Swine feed \\
\hline$[108]$ & $\begin{array}{l}\text { QCM sensor having MIP layer bearing the functional } \\
\text { monomer AA }\end{array}$ & Glucose & Aqueous solutions \\
\hline [109] & $\begin{array}{l}\text { QCM sensor having MIP layer bearing the functional } \\
\text { monomer MAA }\end{array}$ & Microcystin & Lake water \\
\hline$[110]$ & $\begin{array}{l}\text { QCM sensor having MIP layer bearing the functional } \\
\text { monomer 1-Vinyl-2-pyrrolidone }\end{array}$ & Heparin & Plasma \\
\hline [111] & $\begin{array}{l}\text { QCM sensor having MIP layer bearing the functional } \\
\text { monomer MAA }\end{array}$ & Methimazole & Urine \\
\hline [112] & $\begin{array}{c}\text { QCM sensor having MIP layer bearing zinc acrylate as } \\
\text { the functional monomer }\end{array}$ & Human serum albumin & Human serum \\
\hline$[113]$ & $\begin{array}{c}\text { QCM sensor having MIP layer bearing } \\
\text { 3-aminopropyltriethoxysilane as the functional } \\
\text { monomer }\end{array}$ & Enrofloxacin & $\begin{array}{l}\text { Milk, egg, chicken } \\
\text { muscle and pork }\end{array}$ \\
\hline
\end{tabular}

elimination reactions. The functional monomer 4-VP and template compound 5-nitro indole were used for the synthesis of imprinted nanogels. The results showed that the prepared 5-nitro indole imprinted nanogels exhibited high catalytic activity towards the substrate 1,2-benzisoxazole. Substrate selectivity of the prepared catalytic nanogels was also investigated using 5-Cl-benzisoxazole which is a substrate analogue. The catalytic nanogels displayed lower affinity towards 5-Cl-benzisoxazole compared to the substrate 1,2benzisoxazole.

In another interesting study, Zhou and colleagues prepared a molecularly imprinted $\mathrm{TiO}_{2}$ photocatalyst having thiol groups for the efficient removal of 2,4dinitrophenol from wastewater [147]. MIP-based $\mathrm{TiO}_{2}$ photocatalyst was prepared in water as a green solvent using o-phenylenediamine as the functional monomer. The results confirmed that the prepared MIP-based green photocatalyst displayed excellent selectivity and degradation activity towards 2,4-DNP in wastewater.

\section{Conclusions}

The growing number of published researches in which nanostructured composite MIPs have been used for different applications showed that these are promising materials for the selective extraction, sensing, and catalysis. The reported studies described in this review highlight the recent progress in SPE, sensors, and catalytic systems using nanostructured composite MIPs over the past years. Composite MIPs in nanoscale as promising materials provide a new approach for the selective SPE and sensors towards target molecules in complex matrices. On the other hand, these materials offer new routes to control aspects that determine the stereochemical outcome of a catalysis reaction.

\section{Conflicts of Interest}

The authors declare that they have no conflicts of interest.

\section{References}

[1] B. Sellergren and F. Lanza, Molecularly Imprinted Polymers: Man-made mimics of antibodies and their application in analytical chemistry: Techniques and instrumentation in analytical chemistry, Elsevier Science, Amsterdam, Netherlands, 2001.

[2] D. R. Kryscio and N. A. Peppas, "Critical review and perspective of macromolecularly imprinted polymers," Acta Biomaterialia, vol. 8, no. 2, pp. 461-473, 2012.

[3] W. J. Cheong, S. H. Yang, and F. Ali, "Molecular imprinted polymers for separation science: a review of reviews," Journal of Separation Science, vol. 36, no. 3, pp. 609-628, 2013. 
[4] G. Vasapollo, R. D. Sole, L. Mergola et al., "Molecularly imprinted polymers: present and future prospective," International Journal of Molecular Sciences, vol. 12, no. 9, pp. 5908-5945, 2011.

[5] Z. Chen, M. Wang, Y. Fu, H. Yu, and D. Di, "Preparation of quercetin molecularly imprinted polymers," Designed Monomers and Polymers, vol. 15, no. 1, pp. 93-111, 2012.

[6] J. R. L. Guerreiro, V. Freitas, and M. G. F. Sales, "New sensing materials of molecularly-imprinted polymers for the selective recognition of Chlortetracycline," Microchemical Journal, vol. 97, no. 2, pp. 173-181, 2011.

[7] E. P. C. Lai and S. Y. Feng, "Molecularly imprinted solid phase extraction for rapid screening of metformin," Microchemical Journal, vol. 75, no. 3, pp. 159-168, 2003.

[8] Z. Zhang, D. Niu, Y. Li, and J. Shi, "Magnetic, core-shell structured and surface molecularly imprinted polymers for the rapid and selective recognition of salicylic acid from aqueous solutions," Applied Surface Science, vol. 435, pp. 178-186, 2018.

[9] R. Sedghi, M. Yassari, and B. Heidari, "Thermo-responsive molecularly imprinted polymer containing magnetic nanoparticles: Synthesis, characterization and adsorption properties for curcumin," Colloids and Surfaces B: Biointerfaces, vol. 162, pp. 154-162, 2018.

[10] W. Ji, Y. Guo, X. Wang, and D. Guo, "A water-compatible magnetic molecularly imprinted polymer for the selective extraction of risperidone and 9-hydroxyrisperidone from human urine," Talanta, vol. 181, pp. 392-400, 2018.

[11] X. Pan, X. He, and Z. Liu, "Molecularly imprinted mesoporous silica nanoparticles for specific extraction and efficient identification of Amadori compounds," Analytica Chimica Acta, vol. 1019, pp. 65-73, 2018.

[12] J. Kupai, M. Razali, S. Buyuktiryaki, R. Kecili, and G. Szekely, "Long-term stability and reusability of molecularly imprinted polymers," Polymer Chemistry, vol. 8, no. 4, pp. 666-673, 2017.

[13] C. Alexander, L. Davidson, and W. Hayes, "Imprinted polymers: artificial molecular recognition materials with applications in synthesis and catalysis," Tetrahedron, vol. 59, no. 12, pp. 20252057, 2003.

[14] D. Mathew, B. Thomas, and K. Devaky, "Biomimetic recognition and peptidase activities of transition state analogue imprinted chymotrypsin mimics," Reactive and Functional Polymers, vol. 124, pp. 121-128, 2018.

[15] H. Chen, Z. Zhang, L. Luo, and S. Yao, "Surface-imprinted chitosan-coated magnetic nanoparticles modified multi-walled carbon nanotubes biosensor for detection of bovine serum albumin," Sensors and Actuators B: Chemical, vol. 163, no. 1, pp. 76-83, 2012.

[16] M. Cui, J. Huang, Y. Wang, Y. Wu, and X. Luo, "Molecularly imprinted electrochemical sensor for propyl gallate based on PtAu bimetallic nanoparticles modified graphene-carbon nanotube composites," Biosensors and Bioelectronics, vol. 68, pp. 563-569, 2015.

[17] B. B. Prasad, R. Madhuri, M. P. Tiwari, and P. S. Sharma, "Imprinting molecular recognition sites on multiwalled carbon nanotubes surface for electrochemical detection of insulin in real samples," Electrochimica Acta, vol. 55, no. 28, pp. 9146-9156, 2010.

[18] A. Afzal and F. Dickert, "Imprinted Oxide and MIP/Oxide Hybrid Nanomaterials for Chemical Sensors," Nanomaterials, vol. 8, no. 4, p. 257, 2018.

[19] I. Liška, "Fifty years of solid-phase extraction in water analysis - Historical development and overview," Journal of Chromatography $A$, vol. 885, no. 1-2, pp. 3-16, 2000.
[20] J. Cazes, Encyclopedia of Chromatography, CRC Press, Germany, 2009.

[21] B. Y. Spivakov, G. I. Malofeeva, and O. M. Petrukhin, "Solidphase extraction on alkyl-bonded silica gels in inorganic analysis," Analytical Sciences, vol. 22, no. 4, pp. 503-519, 2006.

[22] K. Pyrzynska, "Application of carbon sorbents for the concentration and separation of metal ions," Analytical Sciences, vol. 23, no. 6, pp. 631-637, 2007.

[23] J. A. Rodríguez, K. A. Escamilla-Lara, A. Guevara-Lara, J. M. Miranda, and M. E. Páez-Hernández, "Application of an activated carbon-based support for magnetic solid phase extraction followed by spectrophotometric determination of tartrazine in commercial beverages," International Journal of Analytical Chemistry, vol. 2015, Article ID 291827, 8 pages, 2015.

[24] M. G. Valdés, A. Pérez-Cordoves, and M. Díaz-García, “Zeolites and zeolite-based materials in analytical chemistry," $\operatorname{Tr} A C$ Trends in Analytical Chemistry, vol. 25, no. 1, pp. 24-30, 2006.

[25] X. Shen, L. Zhu, N. Wang, L. Ye, and H. Tang, "Molecular imprinting for removing highly toxic organic pollutants," Chemical Communications, vol. 48, no. 6, pp. 788-798, 2012.

[26] P. Su, R. Wang, Y. Yu, and Y. Yang, "Microwave-assisted synthesis of ionic liquid-modified silica as a sorbent for the solid-phase extraction of phenolic compounds from water," Analytical Methods, vol. 6, no. 3, pp. 704-709, 2014.

[27] R.-Z. Wang, D.-L. Huang, Y.-G. Liu et al., "Selective removal of BPA from aqueous solution using molecularly imprinted polymers based on magnetic graphene oxide," RSC Advances, vol. 6, no. 108, pp. 106201-106210, 2016.

[28] W. Shen, G. Xu, F. Wei, J. Yang, Z. Cai, and Q. Hu, "Preparation and application of imprinted polymer for tetrabromobisphenol A using tetrachlorobisphenol A as the dummy template," Analytical Methods, vol. 5, no. 19, pp. 5208-5214, 2013.

[29] B. Sellergren, "Direct Drug Determination by Selective Sample Enrichment on an Imprinted Polymer," Analytical Chemistry, vol. 66, no. 9, pp. 1578-1582, 1994.

[30] E. Caro, R. M. Marcé, P. A. G. Cormack, D. C. Sherrington, and F. Borrull, "On-line solid-phase extraction with molecularly imprinted polymers to selectively extract substituted 4-chlorophenols and 4-nitrophenol from water," Journal of Chromatography A, vol. 995, no. 1-2, pp. 233-238, 2003.

[31] F. Chapuis, V. Pichon, F. Lanza, B. Sellergren, and M.-C. Hennion, "Retention mechanism of analytes in the solidphase extraction process using molecularly imprinted polymers: Application to the extraction of triazines from complex matrices," Journal of Chromatography B, vol. 804, no. 1, pp. 93$101,2004$.

[32] J.-P. Lai, R. Niessner, and D. Knopp, “Benzo[a]pyrene imprinted polymers: Synthesis, characterization and SPE application in water and coffee samples," Analytica Chimica Acta, vol. 522, no. 2, pp. 137-144, 2004.

[33] O. Brüggemann, A. Visnjevski, R. Burch, and P. Patel, "Selective extraction of antioxidants with molecularly imprinted polymers," Analytica Chimica Acta, vol. 504, no. 1, pp. 81-88, 2004.

[34] F. Puoci, A. Scoma, G. Cirillo, L. Bertin, F. Fava, and N. Picci, "Selective extraction and purification of gallic acid from actual site olive mill wastewaters by means of molecularly imprinted microparticles," Chemical Engineering Journal, vol. 198-199, pp. 529-535, 2012. 
[35] J. H. Xin, X. G. Qiao, Z. X. Xu, and J. Zhou, "Molecularly imprinted polymer as sorbent for solid-phase extraction coupling to gas chromatography for the simultaneous determination of trichlorfon and monocrotophos residues in vegetables," Food Analytical Methods, vol. 6, no. 1, pp. 274-281, 2013.

[36] Y. Li, C. Zheng, X. Sun, B. Ouyang, P. Ni, and Y. Zhang, "Identification of 3-chloro-1,2-propandiol using molecularly imprinted composite solid-phase extraction materials," Analytical and Bioanalytical Chemistry, vol. 406, no. 25, pp. 6319-6327, 2014.

[37] X. He, X. Mei, J. Wang, Z. Lian, L. Tan, and W. Wu, "Determination of diethylstilbestrol in seawater by molecularly imprinted solid-phase extraction coupled with high-performance liquid chromatography," Marine Pollution Bulletin, vol. 102, no. 1, pp. 142-147, 2016.

[38] S. Han, X. Li, Y. Wang, and S. Chen, "Multifunctional imprinted polymers based on $\mathrm{CdTe} / \mathrm{CdS}$ and magnetic graphene oxide for selective recognition and separation of p-t-octylphenol," Chemical Engineering Journal, vol. 271, pp. 87-95, 2015.

[39] E. C. Morais, R. Brambilla, G. G. Correa, V. Dalmoro, and J. H. Z. Dos Santos, "Imprinted silicas for paracetamol preconcentration prepared by the sol-gel process," Journal of Sol-Gel Science and Technology, vol. 83, no. 1, pp. 90-99, 2017.

[40] I. Vasconcelos and C. Fernandes, "Magnetic solid phase extraction for determination of drugs in biological matrices," $\operatorname{Tr} A C$ Trends in Analytical Chemistry, vol. 89, pp. 41-52, 2017.

[41] S. Ansari and M. Karimi, "Synthesis and application of molecularly imprinted polymer for highly selective solid phase extraction trace amount of sotalol from human urine samples: Optimization by central composite design (CCD)," Medicinal Chemistry Research, vol. 26, no. 10, pp. 2477-2490, 2017.

[42] S. Hassanpour, M. Taghizadeh, and Y. Yamini, "Magnetic $\mathrm{Cr}(\mathrm{VI})$ Ion Imprinted Polymer for the Fast Selective Adsorption of $\mathrm{Cr}(\mathrm{VI})$ from Aqueous Solution," Journal of Polymers and the Environment, pp. 1-15, 2017.

[43] J. Fasihi, M. Shamsipur, A. Khanchi, M. Mahani, and K. Ashtari, "Imprinted polymer grafted from silica particles for on-line trace enrichment and ICP OES determination of uranyl ion," Microchemical Journal, vol. 126, pp. 316-321, 2016.

[44] N. Khoddami and F. Shemirani, "A new magnetic ion-imprinted polymer as a highly selective sorbent for determination of cobalt in biological and environmental samples," Talanta, vol. 146, pp. 244-252, 2016.

[45] Y. Chen, X. Ma, M. Huang, J. Peng, and C. Li, "Use of a new magnetic ion-imprinted nanocomposite adsorbent for selective and rapid preconcentration and determination of trace nickel by flame atomic absorption spectrometry," Analytical Methods, vol. 8, no. 4, pp. 824-829, 2016.

[46] M. Zhao, X. Ma, F. Zhao, and H. Guo, "Molecularly imprinted polymer silica monolith for the selective extraction of alphacypermethrin from soil samples," Journal of Materials Science, vol. 51, no. 7, pp. 3440-3447, 2016.

[47] H. Lian, Y. Hu, and G. Li, "Novel metal-ion-mediated, compleximprinted solid-phase microextraction fiber for the selective recognition of thiabendazole in citrus and soil samples," Journal of Separation Science, vol. 37, no. 1-2, pp. 106-113, 2014.

[48] S. Xu, C. Guo, Y. Li, Z. Yu, C. Wei, and Y. Tang, "Methyl parathion imprinted polymer nanoshell coated on the magnetic nanocore for selective recognition and fast adsorption and separation in soils," Journal of Hazardous Materials, vol. 264, pp. 34-41, 2014.
[49] Y. Hao, R. Gao, L. Shi, D. Liu, Y. Tang, and Z. Guo, "Watercompatible magnetic imprinted nanoparticles served as solidphase extraction sorbents for selective determination of trace 17beta-estradiol in environmental water samples by liquid chromatography," Journal of Chromatography A, vol. 1396, pp. 7-16, 2015.

[50] K. Kamari and A. Taheri, "Preparation and evaluation of magnetic core-shell mesoporous molecularly imprinted polymers for selective adsorption of amitriptyline in biological samples," Journal of the Taiwan Institute of Chemical Engineers, vol. 86, pp. 230-239, 2018.

[51] A. Ostovan, M. Ghaedi, and M. Arabi, "Fabrication of watercompatible superparamagnetic molecularly imprinted biopolymer for clean separation of baclofen from bio-fluid samples: A mild and green approach," Talanta, vol. 179, pp. 760-768, 2018.

[52] M. Soleimani, M. Ahmadi, T. Madrakian, and A. Afkhami, "Magnetic solid phase extraction of rizatriptan in human urine samples prior to its spectrofluorimetric determination," Sensors and Actuators B: Chemical, vol. 254, pp. 1225-1233, 2018.

[53] S. Azodi-Deilami, A. H. Najafabadi, E. Asadi, M. Abdouss, and D. Kordestani, "Magnetic molecularly imprinted polymer nanoparticles for the solid-phase extraction of paracetamol from plasma samples, followed its determination by HPLC," Microchimica Acta, vol. 181, no. 15-16, pp. 1823-1832, 2014.

[54] A. Rajabi Khorrami and A. Rashidpur, "Development of a fiber coating based on molecular sol-gel imprinting technology for selective solid-phase micro extraction of caffeine from human serum and determination by gas chromatography/mass spectrometry," Analytica Chimica Acta, vol. 727, pp. 20-25, 2012.

[55] J. Meng, W. Zhang, T. Bao, and Z. Chen, "Novel molecularly imprinted magnetic nanoparticles for the selective extraction of protoberberine alkaloids in herbs and rat plasma," Journal of Separation Science, vol. 38, no. 12, pp. 2117-2125, 2015.

[56] J.-B. Ma, H.-W. Qiu, Q.-H. Rui et al., "Fast determination of catecholamines in human plasma using carboxyl-functionalized magnetic-carbon nanotube molecularly imprinted polymer followed by liquid chromatography-tandem quadrupole mass spectrometry," Journal of Chromatography A, vol. 1429, pp. 8696, 2016.

[57] G. Sheykhaghaei, M. Hossainisadr, S. Khanahmadzadeh, M. Seyedsajadi, and A. Alipouramjad, "Magnetic molecularly imprinted polymer nanoparticles for selective solid phase extraction and pre-concentration of Tizanidine in human urine," Journal of Chromatography B, vol. 1011, pp. 1-5, 2016.

[58] T. Madrakian, F. Fazl, M. Ahmadi, and A. Afkhami, "Efficient solid phase extraction of codeine from human urine samples using a novel magnetic molecularly imprinted nanoadsorbent and its spectrofluorometric determination," New Journal of Chemistry, vol. 40, no. 1, pp. 122-129, 2016.

[59] X. Gu, H. He, C.-Z. Wang et al., "Synthesis of surface nanomolecularly imprinted polymers for sensitive baicalin detection in biological samples," RSC Advances, vol. 5, no. 52, pp. 4137741384, 2015.

[60] G. Liang, H. Zhai, L. Huang et al., "Synthesis of carbon quantum dots-doped dummy molecularly imprinted polymer monolithic column for selective enrichment and analysis of aflatoxin B1 in peanut," Journal of Pharmaceutical and Biomedical Analysis, vol. 149, pp. 258-264, 2018.

[61] R. Garcia, E. P. Carreiro, J. P. Prates Ramalho et al., "A magnetic controllable tool for the selective enrichment of dimethoate from olive oil samples: A responsive molecular imprintingbased approach," Food Chemistry, vol. 254, pp. 309-316, 2018. 
[62] M. Hashemi and Z. Nazari, "Preparation of molecularly imprinted polymer based on the magnetic multiwalled carbon nanotubes for selective separation and spectrophotometric determination of melamine in milk samples," Journal of Food Composition and Analysis, vol. 69, pp. 98-106, 2018.

[63] M. Wei, X. Yan, S. Liu, and Y. Liu, "Preparation and evaluation of superparamagnetic core-shell dummy molecularly imprinted polymer for recognition and extraction of organophosphorus pesticide," Journal of Materials Science, vol. 53, no. 7, pp. 48974912, 2018.

[64] N. Kumar, N. Narayanan, and S. Gupta, "Application of magnetic molecularly imprinted polymers for extraction of imidacloprid from eggplant and honey," Food Chemistry, vol. 255, pp. 81-88, 2018.

[65] J. L. Urraca, J. F. Huertas-Pérez, G. A. Cazorla, J. GraciaMora, A. M. García-Campaña, and M. C. Moreno-Bondi, "Development of magnetic molecularly imprinted polymers for selective extraction: Determination of citrinin in rice samples by liquid chromatography with UV diode array detection," Analytical and Bioanalytical Chemistry, vol. 408, no. 11, pp. 3033-3042, 2016.

[66] Z.-Z. Lin, H.-Y. Zhang, L. Li, and Z.-Y. Huang, "Application of magnetic molecularly imprinted polymers in the detection of malachite green in fish samples," Reactive and Functional Polymers, vol. 98, pp. 24-30, 2016.

[67] S. Aggarwal, Y. S. Rajput, G. Singh, and R. Sharma, "Synthesis and characterization of oxytetracycline imprinted magnetic polymer for application in food," Applied Nanoscience, vol. 6, no. 2, pp. 209-214, 2016.

[68] L. Xu, G. Fang, M. Pan, X. Wang, and S. Wang, "Onepot synthesis of carbon dots-embedded molecularly imprinted polymer for specific recognition of sterigmatocystin in grains," Biosensors and Bioelectronics, vol. 77, pp. 950-956, 2016.

[69] X. Hu, L. Xie, J. Guo et al., "Hydrophilic gallic acid-imprinted polymers over magnetic mesoporous silica microspheres with excellent molecular recognition ability in aqueous fruit juices," Food Chemistry, vol. 179, pp. 206-212, 2015.

[70] A. A. Asgharinezhad, N. Jalilian, H. Ebrahimzadeh, and Z. Panjali, "A simple and fast method based on new magnetic ion imprinted polymer nanoparticles for the selective extraction of $\mathrm{Ni}(\mathrm{ii})$ ions in different food samples," RSC Advances, vol. 5, no. 56, pp. 45510-45519, 2015.

[71] W. J. Tang, T. Zhao, C. H. Zhou, X. J. Guan, and H. X. Zhang, "Preparation of hollow molecular imprinting polymer for determination of ofloxacin in milk," Anal. Methods, vol. 6, no. 10, pp. 3309-3315, 2014.

[72] L. Qiao, N. Gan, F. Hu et al., "Magnetic nanospheres with a molecularly imprinted shell for the preconcentration of diethylstilbestrol," Microchimica Acta, vol. 181, no. 11-12, pp. 1341-1351, 2014.

[73] Y. Hu, Y. Li, R. Liu, W. Tan, and G. Li, "Magnetic molecularly imprinted polymer beads prepared by microwave heating for selective enrichment of $\beta$-agonists in pork and pig liver samples," Talanta, vol. 84, no. 2, pp. 462-470, 2011.

[74] L. Chen and B. Li, "Magnetic molecularly imprinted polymer extraction of chloramphenicol from honey," Food Chemistry, vol. 141, no. 1, pp. 23-28, 2013.

[75] A. Nezhadali, L. Mehri, and R. Shadmehri, "Determination of methimazole based on electropolymerized-molecularly imprinted polypyrrole modified pencil graphite sensor," Materials Science and Engineering C, vol. 85, pp. 225-232, 2018.
[76] H. Bai, C. Wang, J. Chen, Z. Li, K. Fu, and Q. Cao, "Graphene@AuNPs modified molecularly imprinted electrochemical sensor for the determination of colchicine in pharmaceuticals and serum," Journal of Electroanalytical Chemistry, vol. 816, pp. 7-13, 2018.

[77] Z. Zhang, Y. Li, X. Liu, Y. Zhang, and D. Wang, "Molecular Imprinting Electrochemical sensor for sensitive creatinine determination," International Journal of Electrochemical Science, vol. 13, pp. 2986-2995, 2018.

[78] B. Deiminiat, G. H. Rounaghi, and M. H. Arbab-Zavar, "Development of a new electrochemical imprinted sensor based on poly-pyrrole, sol-gel and multiwall carbon nanotubes for determination of tramadol," Sensors and Actuators B: ChemicalSensors and Actuators B: Chemical, vol. 238, pp. 651-659, 2017.

[79] A. Shirzadmehr, M. Rezaei, H. Bagheri, and H. Khoshsafar, "Novel potentiometric sensor for the trace-level determination of $\mathrm{Zn}^{2+}$ based on a new nanographene/ion imprinted polymer composite," International Journal of Environmental Analytical Chemistry, vol. 96, no. 10, pp. 1-16, 2016.

[80] M. A. Abu-Dalo, N. S. Nassory, N. I. Abdulla, and I. R. AlMheidat, "Azithromycin-molecularly imprinted polymer based on PVC membrane for Azithromycin determination in drugs using coated graphite electrode," Journal of Electroanalytical Chemistry, vol. 751, pp. 75-79, 2015.

[81] S. Azodi-Deilami, E. Asadi, M. Abdouss, F. Ahmadi, A. H. Najafabadi, and S. Farzaneh, "Determination of meloxicam in plasma samples using a highly selective and sensitive voltammetric sensor based on carbon paste electrodes modified by molecularly imprinted polymer nanoparticle-multiwall carbon nanotubes," Analytical Methods, vol. 7, no. 4, pp. 1280-1292, 2015.

[82] J. Chen, H. Huang, Y. Zeng, H. Tang, and L. Li, "A novel composite of molecularly imprinted polymer-coated PdNPs for electrochemical sensing norepinephrine," Biosensors and Bioelectronics, vol. 65, pp. 366-374, 2015.

[83] N. A. El Gohary, A. Madbouly, R. M. El Nashar, and B. Mizaikoff, "Synthesis and application of a molecularly imprinted polymer for the voltammetric determination of famciclovir," Biosensors and Bioelectronics, vol. 65, pp. 108-114, 2015.

[84] H. Bai, C. Wang, J. Chen, J. Peng, and Q. Cao, "A novel sensitive electrochemical sensor based on in-situ polymerized molecularly imprinted membranes at graphene modified electrode for artemisinin determination," Biosensors and Bioelectronics, vol. 64, pp. 352-358, 2015.

[85] X. Zhang, Y. Peng, J. Bai et al., "A novel electrochemical sensor based on electropolymerized molecularly imprinted polymer and gold nanomaterials amplification for estradiol detection," Sensors and Actuators B: Chemical, vol. 200, pp. 69-75, 2014.

[86] S. Antwi-Boampong, K. S. Mani, J. Carlan, and J. J. Belbruno, "A selective molecularly imprinted polymer-carbon nanotube sensor for cotinine sensing," Journal of Molecular Recognition, vol. 27, no. 1, pp. 57-63, 2014.

[87] L. Zhao, B. Zeng, and F. Zhao, "Electrochemical determination of tartrazine using a molecularly imprinted polymer - Multiwalled carbon nanotubes - ionic liquid supported Pt nanoparticles composite film coated electrode," Electrochimica Acta, vol. 146, pp. 611-617, 2014.

[88] H. Chen, Z. Zhang, R. Cai, W. Rao, and F. Long, "Molecularly imprinted electrochemical sensor based on nickel nanoparticles-graphene nanocomposites modified electrode 
for determination of tetrabromobisphenol A," Electrochimica Acta, vol. 117, pp. 385-392, 2014.

[89] R. Cai, W. Rao, Z. Zhang, F. Long, and Y. Yin, "An imprinted electrochemical sensor for bisphenol A determination based on electrodeposition of a graphene and Ag nanoparticle modified carbon electrode," Analytical Methods, vol. 6, no. 5, pp. 15901597, 2014.

[90] T. Alizadeh, "Preparation of magnetic TNT-imprinted polymer nanoparticles and their accumulation onto magnetic carbon paste electrode for TNT determination," Biosensors and Bioelectronics, vol. 61, pp. 532-540, 2014.

[91] Y. Wan, Y. Liu, C. Liu et al., "Rapid determination of neomycin in biological samples using fluorescent sensor based on quantum dots with doubly selective binding sites," Journal of Pharmaceutical and Biomedical Analysis, vol. 154, pp. 75-84, 2018.

[92] Q. Liu, M. Jiang, Z. Ju, X. Qiao, and Z. Xu, "Development of direct competitive biomimetic immunosorbent assay based on quantum dot label for determination of trichlorfon residues in vegetables," Food Chemistry, vol. 250, pp. 134-139, 2018.

[93] Y. Ma, H. Li, and L. Wang, "Magnetic-luminescent bifunctional nanosensors," Journal of Materials Chemistry, vol. 22, no. 36, pp. 18761-18767, 2012.

[94] F. Lu, H. Li, M. Sun et al., "Flow injection chemiluminescence sensor based on core-shell magnetic molecularly imprinted nanoparticles for determination of sulfadiazine," Analytica Chimica Acta, vol. 718, pp. 84-91, 2012.

[95] H. Bao, T. Wei, H. Meng, and B. Liu, "Surface Plasmon resonance sensor for supersensitive detection of clenbuterol using molecularly imprinted film," Chemistry Letters, vol. 41, no. 3, pp. 237-239, 2012.

[96] N. Zhao, C. Chen, and J. Zhou, "Surface plasmon resonance detection of ametryn using a molecularly imprinted sensing film prepared by surface-initiated atom transfer radical polymerization," Sensors and Actuators B: Chemical, vol. 166-167, pp. 473-479, 2012.

[97] L. Dan and H.-F. Wang, "Mn-doped ZnS quantum dot imbedded two-fragment imprinting silica for enhanced room temperature phosphorescence probing of domoic acid," Analytical Chemistry, vol. 85, no. 10, pp. 4844-4848, 2013.

[98] M.-H. Lee, J. L. Thomas, Y.-L. Chen et al., "Optical sensing of urinary melatonin with molecularly imprinted poly(ethyleneco-vinyl alcohol) coated zinc oxide nanorod arrays," Biosensors and Bioelectronics, vol. 47, pp. 56-61, 2013.

[99] M. Ahmadi, T. Madrakian, and A. Afkhami, "Molecularly imprinted polymer coated magnetite nanoparticles as an efficient mefenamic acid resonance light scattering nanosensor," Analytica Chimica Acta, vol. 852, pp. 250-256, 2014.

[100] N. Cennamo, G. D’Agostino, M. Pesavento, and L. Zeni, "High selectivity and sensitivity sensor based on MIP and SPR in tapered plastic optical fibers for the detection of 1-nicotine," Sensors and Actuators B: Chemical, vol. 191, pp. 529-536, 2014.

[101] X. Zhou, A. Wang, C. Yu, S. Wu, and J. Shen, "Facile Synthesis of Molecularly Imprinted Graphene Quantum Dots for the Determination of Dopamine with Affinity-Adjustable," Applied Materials \& Interfaces, vol. 7, no. 22, pp. 11741-11747, 2015.

[102] W.-H. Zhou, S.-F. Tang, Q.-H. Yao, F.-R. Chen, H.-H. Yang, and X.-R. Wang, "A quartz crystal microbalance sensor based on mussel-inspired molecularly imprinted polymer," Biosensors and Bioelectronics, vol. 26, no. 2, pp. 585-589, 2010.

[103] N. Iqbal, G. Mustafa, A. Rehman et al., "QCM-Arrays for sensing terpenes in fresh and dried herbs via bio-mimetic MIP layers," Sensors, vol. 10, no. 7, pp. 6361-6376, 2010.
[104] R. Madhuri, M. P. Tiwari, D. Kumar, A. Mukharji, and B. B. Prasad, "Biomimetic piezoelectric quartz sensor for folic acid based on a molecular imprinting technology," Advanced Materials Letters, vol. 2, no. 4, pp. 264-267, 2011.

[105] U. Latif, A. Mujahid, A. Afzal, R. Sikorski, P. A. Lieberzeit, and F. L. Dickert, "Dual and tetraelectrode QCMs using imprinted polymers as receptors for ions and neutral analytes," Analytical and Bioanalytical Chemistry, vol. 400, no. 8, pp. 2507-2515, 2011.

[106] A. V. Vergara, R. B. Pernites, S. Pascua, C. A. Binag, and R. C. Advincula, "QCM sensing of a chemical nerve agent analog via electropolymerized molecularly imprinted polythiophene films," Journal of Polymer Science Part A: Polymer Chemistry, vol. 50, no. 4, pp. 675-685, 2012.

[107] L.-J. Kong, M.-F. Pan, G.-Z. Fang et al., "Molecularly imprinted quartz crystal microbalance sensor based on poly(o-aminothiophenol) membrane and Au nanoparticles for ractopamine determination," Biosensors and Bioelectronics, vol. 51, pp. 286-292, 2014.

[108] A. Mirmohseni, R. Pourata, and M. Shojaei, "Application of molecularly imprinted polymer for determination of glucose by quartz crystal nanobalance technique," IEEE Sensors Journal, vol. 14, no. 8, pp. 2807-2812, 2014.

[109] H. He, L. Zhou, Y. Wang et al., "Detection of trace microcystinLR on a $20 \mathrm{MHz}$ QCM sensor coated with in situ self-assembled MIPs," Talanta, vol. 131, pp. 8-13, 2015.

[110] M. Hussain, "Ultra-sensitive detection of heparin via aPTT using plastic antibodies on QCM-D platform," RSC Advances, vol. 5, no. 68, pp. 54963-54970, 2015.

[111] M. Pan, G. Fang, Y. Lu, L. Kong, Y. Yang, and S. Wang, "Molecularly imprinted biomimetic QCM sensor involving a poly(amidoamine) dendrimer as a functional monomer for the highly selective and sensitive determination of methimazole," Sensors and Actuators, vol. 207, pp. 588-595, 2015.

[112] X.-T. Ma, X.-W. He, W.-Y. Li, and Y.-K. Zhang, "Epitope molecularly imprinted polymer coated quartz crystalmicrobalance sensor for the determination of human serum albumin," Sensors and Actuators B, vol. 246, pp. 879-886, 2017.

[113] M. Pan, Y. Gu, M. Zhang, J. Wang, Y. Yun, and S. Wang, "Reproducible Molecularly Imprinted QCM Sensor for Accurate, Stable, and Sensitive Detection of Enrofloxacin Residue in Animal-Derived Foods," Food Analytical Methods, vol. 11, no. 2, pp. 495-503, 2017.

[114] Y. Su, B. Qiu, C. Chang et al., "Separation of bovine hemoglobin using novel magnetic molecular imprinted nanoparticles," RSC Advances, vol. 8, no. 11, pp. 6192-6199, 2018.

[115] R. Viveiros, F. M. Dias, L. B. Maia, W. Heggie, and T. Casimiro, "Green strategy to produce large core-shell affinity beads for gravity-driven API purification processes," Journal of Industrial and Engineering Chemistry, vol. 54, pp. 341-349, 2017.

[116] Z. Zhang, X. Chen, W. Rao, H. Chen, and R. Cai, "Synthesis and properties of magnetic molecularly imprinted polymers based on multiwalled carbon nanotubes for magnetic extraction of bisphenol A from water," Journal of Chromatography B, vol. 965, pp. 190-196, 2014.

[117] Y. Yang, X. Meng, and Z. Xiao, "Synthesis of a surface molecular imprinting polymer based on silica and its application in the identification of nitrocellulose," RSC Advances, vol. 8, no. 18, pp. 9802-9811, 2018.

[118] W. Chen, M. Xue, F. Xue et al., "Molecularly imprinted hollow spheres for the solid phase extraction of estrogens," Talanta, vol. 140, pp. 68-72, 2015. 
[119] J. Guo, Y. Wang, Y. Liu, C. Zhang, and Y. Zhou, "Magneticgraphene based molecularly imprinted polymer nanocomposite for the recognition of bovine hemoglobin," Talanta, vol. 144, pp. 411-419, 2015.

[120] J. Luo, Y. Gao, K. Tan, W. Wei, and X. Liu, "Preparation of a Magnetic Molecularly Imprinted Graphene Composite Highly Adsorbent for 4-Nitrophenol in Aqueous Medium," ACS Sustainable Chemistry \& Engineering, vol. 4, no. 6, pp. 33163326, 2016.

[121] W. Yang, D. Niu, X. Ni, Z. Zhou, W. Xu, and W. Huang, "Core-Shell Magnetic Molecularly Imprinted Polymer Prepared for Selectively Removed Indole from Fuel Oil," Advances in Polymer Technology, vol. 36, no. 2, pp. 168-176, 2017.

[122] F. Cao, L. Wang, Y. Yao, F. Wu, H. Sun, and S. Lu, "Synthesis and application of a highly selective molecularly imprinted adsorbent based on multiwalled carbon nanotubes for selective removal of perfluorooctanoic acid," Environ. Sci.: Water Res. Technol, 2018, In press.

[123] M. Cui, S. Liu, W. Lian, J. Li, W. Xu, and J. Huang, "A molecularly-imprinted electrochemical sensor based on a graphene-Prussian blue composite-modified glassy carbon electrode for the detection of butylated hydroxyanisole in foodstuffs," Analyst, vol. 138, no. 20, pp. 5949-5955, 2013.

[124] Y. Hu, X. Li, J. Liu, M. Wu, M. Li, and X. Zang, "One-pot synthesis of a fluorescent molecularly imprinted nanosensor for highly selective detection of sulfapyridine in water," Analytical Methods, vol. 10, no. 8, pp. 884-890, 2018.

[125] Y. Wang, H. Duan, L. Li et al., "A chemiluminescence sensor for determination of lysozyme using magnetic graphene oxide multi-walled carbon nanotube surface molecularly imprinted polymers," RSC Advances, vol. 6, no. 15, pp. 12391-12397, 2016.

[126] X. Bi and K.-L. Yang, "On-line monitoring imidacloprid and thiacloprid in celery juice using quartz crystal microbalance," Analytical Chemistry, vol. 81, no. 2, pp. 527-532, 2009.

[127] M. A. Markowitz, P. R. Kust, G. Deng et al., "Catalytic silica particles via templated-directed molecular imprinting," Langmuir, vol. 16, pp. 1759-1765, 2000.

[128] X. B. Luo, F. Deng, L. J. Min et al., "Facile one step synthesis of inorganic-framework molecularly imprinted $\mathrm{TiO} 2 / \mathrm{WO} 3$ nanocomposite and its molecular recognitive photocatalytic degradation of target contaminant," Environmental Science \& Technology, vol. 47, pp. 7404-7412, 2013.

[129] N. R. Stradiotto, H. Yamanaka, and M. V. B. Zanoni, "Electrochemical sensors: A powerful tool in analytical chemistry," Journal of the Brazilian Chemical Society, vol. 14, no. 2, pp. 159173, 2003.

[130] K. Itaya and A. J. Bard, "Chemically Modified Polymer Electrodes: Synthetic Approach Employing Poly(methacryl chloride) Anchors," Analytical Chemistry, vol. 50, no. 11, pp. 14871489, 1978.

[131] X. Kan, T. Liu, H. Zhou, C. Li, and B. Fang, "Molecular imprinting polymer electrosensor based on gold nanoparticles for theophylline recognition and determination," Microchimica Acta, vol. 171, no. 3, pp. 423-429, 2010.

[132] Y. Li, Y. Liu, J. Liu et al., "Molecularly imprinted polymer decorated nanoporous gold for highly selective and sensitive electrochemical sensors," Scientific Reports, vol. 5, no. 1-8, 2015.

[133] P. Gupta and R. N. Goyal, "Graphene and Co-polymer composite based molecularly imprinted sensor for ultratrace determination of melatonin in human biological fluids," RSC Advances, vol. 5, no. 50, pp. 40444-40454, 2015.
[134] B. B. Prasad, D. Kumar, R. Madhuri, and M. P. Tiwari, "Metal ion mediated imprinting for electrochemical enantioselective sensing of l-histidine at trace level," Biosensors and Bioelectronics, vol. 28, no. 1, pp. 117-126, 2011.

[135] R. Wang, K. Yan, F. Wang, and J. Zhang, "A highly sensitive photoelectrochemical sensor for 4-aminophenol based on CdSgraphene nanocomposites and molecularly imprinted polypyrrole," Electrochimica Acta, vol. 121, pp. 102-108, 2014.

[136] J. Tan, H.-F. Wang, and X.-P. Yan, "Discrimination of saccharides with a fluorescent molecular imprinting sensor array based on phenylboronic acid functionalized mesoporous silica," Analytical Chemistry, vol. 81, no. 13, pp. 5273-5280, 2009.

[137] C. Zhang, H. Cui, J. Cai, Y. Duan, and Y. Liu, "Development of Fluorescence Sensing Material Based on CdSe/ZnS Quantum Dots and Molecularly Imprinted Polymer for the Detection of Carbaryl in Rice and Chinese Cabbage," Journal of Agricultural and Food Chemistry, vol. 63, no. 20, pp. 4966-4972, 2015.

[138] M. Mehrzad-Samarin, F. Faridbod, A. S. Dezfuli, and M. R. Ganjali, "A novel metronidazole fluorescent nanosensor based on graphene quantum dots embedded silica molecularly imprinted polymer," Biosensors and Bioelectronics, vol. 92, pp. 618-623, 2017.

[139] H. Li, N. Li, J. Jiang et al., "Molecularly imprinted magnetic microparticles for the simultaneous detection and extraction of Rhodamine B," Sensors and Actuators B: Chemical, vol. 246, pp. 286-292, 2017.

[140] R. Jalili and M. Amjadi, "Bio-inspired molecularly imprinted polymer-green emitting carbon dot composite for selective and sensitive detection of 3-nitrotyrosine as a biomarker," Sensors and Actuators B: Chemical, vol. 255, pp. 1072-1078, 2018.

[141] Z. Altintas, A. Guerreiro, S. A. Piletsky, and I. E. Tothill, "NanoMIP based optical sensor for pharmaceuticals monitoring," Sensors and Actuators B: Chemical, vol. 213, pp. 305-313, 2015.

[142] J. Ashley, Y. Shukor, R. D’Aurelio et al., "Synthesis of molecularly imprinted polymer nanoparticles for $\alpha$ casein detection using surface plasmon resonance as a milk allergen sensor," ACS Sensors, vol. 3, no. 2, pp. 418-424, 2018.

[143] T. Eren, N. Atar, M. L. Yola, and H. Karimi-Maleh, "A sensitive molecularly imprinted polymer based quartz crystal microbalance nanosensor for selective determination of lovastatin in red yeast rice," Food Chemistry, vol. 185, pp. 430-436, 2015.

[144] N. Gao, J. Dong, M. Liu et al., "Development of molecularly imprinted polymer films used for detection of profenofos based on a quartz crystal microbalance sensor," Analyst, vol. 137, no. 5, pp. 1252-1258, 2012.

[145] G. Fang, Y. Yang, H. Zhu et al., "Development and application of molecularly imprinted quartz crystal microbalance sensor for rapid detection of metolcarb in foods," Sensors and Actuators B: Chemical, vol. 251, pp. 720-728, 2017.

[146] P. Bonomi, A. Servant, and M. Resmini, "Modulation of imprinting efficiency in nanogels with catalytic activity in the Kemp elimination," Journal of Molecular Recognition, vol. 25, no. 6, pp. 352-360, 2012.

[147] X. Zhou, C. Lai, D. Huang et al., "Preparation of watercompatible molecularly imprinted thiol-functionalized activated titanium dioxide: Selective adsorption and efficient photodegradation of 2,4-dinitrophenol in aqueous solution," Journal of Hazardous Materials, vol. 346, pp. 113-123, 2018. 

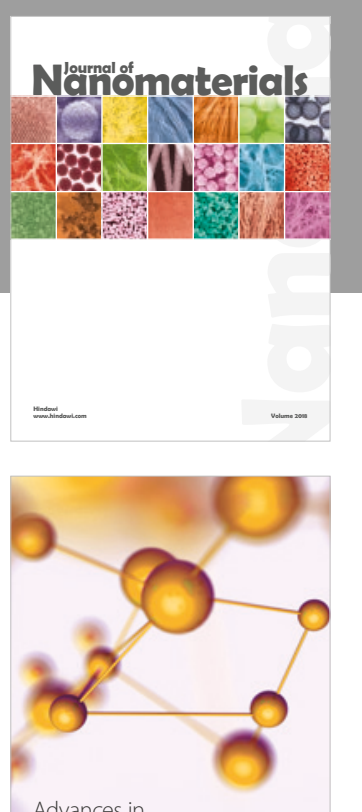

Physical Chemistry
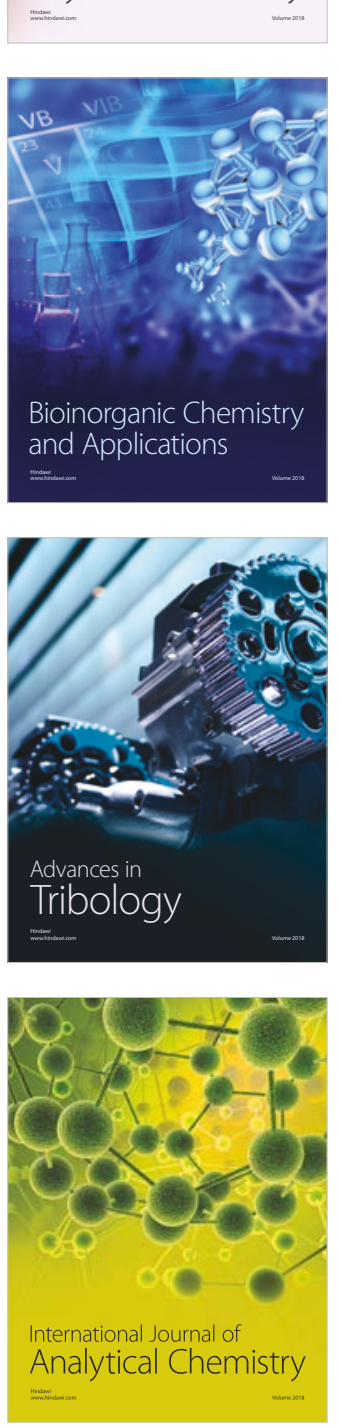

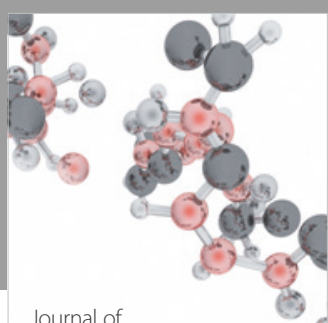

Analytical Methods

in Chemistry

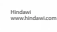

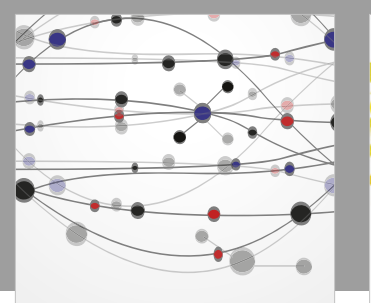

The Scientific World Journal

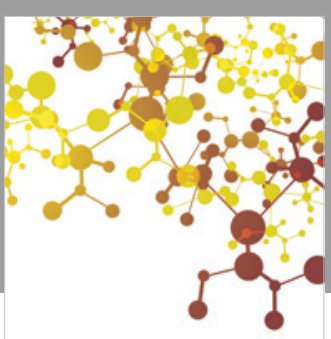

Journal of

Applied Chemistry
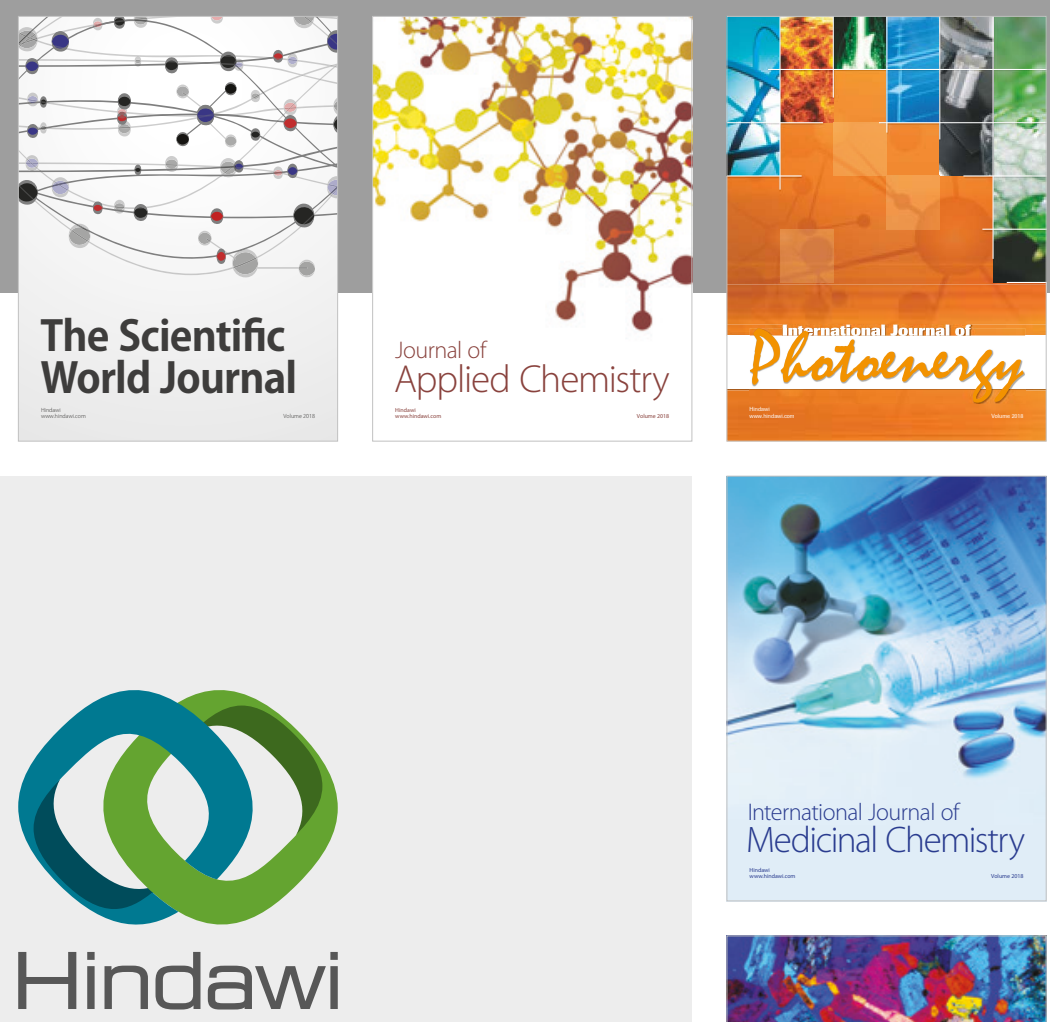

Submit your manuscripts at

www.hindawi.com
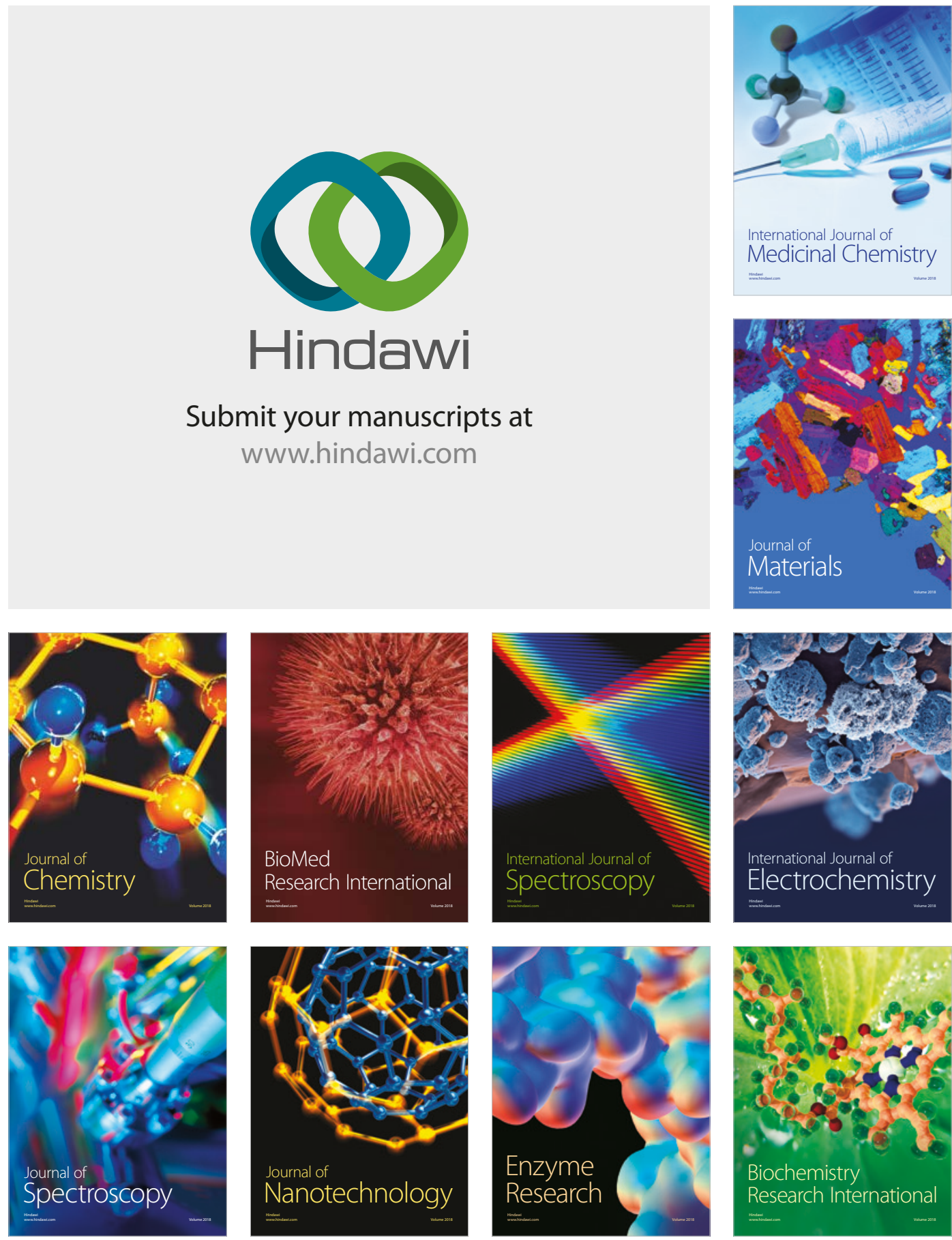
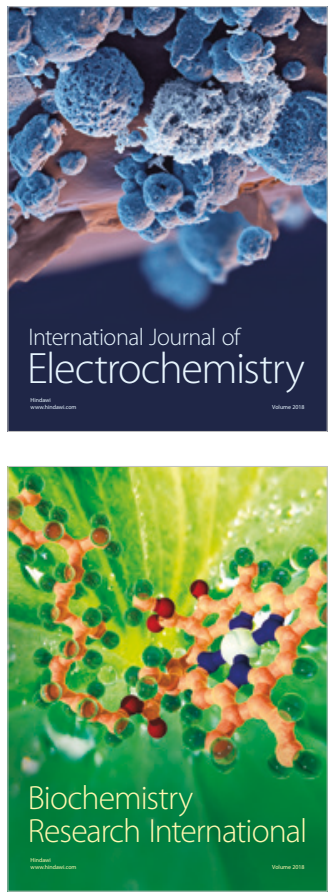